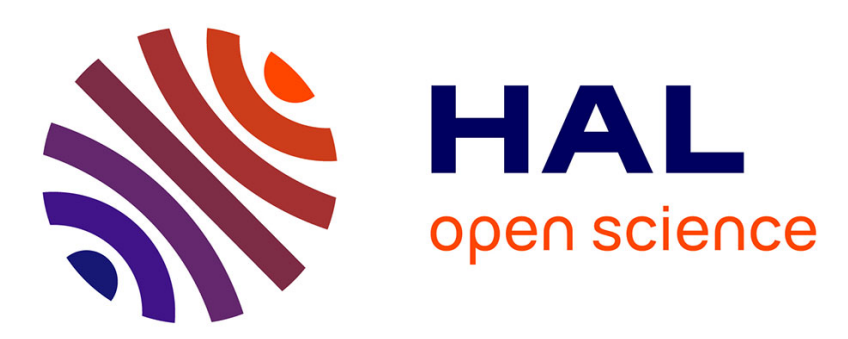

\title{
Evaluation of the impact of strain-dependent permeability on reservoir productivity using iterative coupled reservoir geomechanical modeling
}

\author{
Manouchehr Sanei, Erick S R Santos
}

\section{- To cite this version:}

Manouchehr Sanei, Erick S R Santos. Evaluation of the impact of strain-dependent permeability on reservoir productivity using iterative coupled reservoir geomechanical modeling. Geomechanics and Geophysics for Geo-Energy and Geo-Resources, In press. hal-02871116

\author{
HAL Id: hal-02871116 \\ https://hal.science/hal-02871116
}

Submitted on 17 Jun 2020

HAL is a multi-disciplinary open access archive for the deposit and dissemination of scientific research documents, whether they are published or not. The documents may come from teaching and research institutions in France or abroad, or from public or private research centers.
L'archive ouverte pluridisciplinaire HAL, est destinée au dépôt et à la diffusion de documents scientifiques de niveau recherche, publiés ou non, émanant des établissements d'enseignement et de recherche français ou étrangers, des laboratoires publics ou privés. 


\title{
Evaluation of the impact of strain-dependent permeability on reservoir productivity using iterative coupled reservoir geomechanical modeling
}

\author{
Manouchehr Sanei $^{\mathrm{a}}$, Omar Durán ${ }^{\mathrm{b}}$, Philippe R.B. Devloo ${ }^{\mathrm{c}}$, Erick S.R. \\ Santos $^{\mathrm{d}}$ \\ ${ }^{a}$ Mechanical Engineering Department (FEM) - Petroleum Engineering Division, \\ University of Campinas, Campinas, SP, Brazil \\ ${ }^{b}$ Centre d'Enseignement et de Recherche en Mathématiques et Calcul scientifique, \\ CERMICS (ENPC), Université Paris-Est, Paris, France \\ ${ }^{c}$ Civil Engineering Department (FEC), University of Campinas, Campinas, SP, Brazil \\ ${ }^{d}$ Research and Development Center (Cenpes), Petrobras, Rio de Janeiro, RJ, Brazil
}

\section{Abstract}

Permeability as an important property plays a key role in reservoir performance, numerical reservoir simulation, drilling and production planning. In such reservoirs, stress and strain alters induced by extraction and injection of fluid may substantially change permeability in an irreversible manner. With regard to this phenomenon, several reservoirs may require to consider strain-dependent permeability, in order to have an accurate performance.

In this paper, the strain-dependent permeability is analyzed using coupled reservoir geomechanical modeling. This coupling is implemented using a fixed stress iterative coupled scheme. In this coupling, the fluid flow is presented by Darcy's law with considering nonlinear permeability models. The

\footnotetext{
Email address: Corresponding author: manouchehr.sanei@gmail.com (Manouchehr Sanei)
} 
geomechanical analysis includes the linear part based on Biot's theory and the nonlinear part based on an elastoplastic model. The numerical approximation is done by employing mixed finite element for reservoir flow and a continuous Galerkin finite element for geomechanics. Several numerical simulations are performed to analyze the impact of strain-dependent permeability on reservoir productivity.

Keywords: Strain-dependent permeability, Reservoir productivity, Iterative coupled scheme, Finite element analysis, Reservoir geomechanical modeling.

\section{Introduction}

The reduction of pore pressure during reservoir production changes the initial stress state within the reservoir, which results in increased net stress on reservoir and the surrounding rock (Holt, 1990, Ruistuen et al., 1999). The net stress can cause strain and compaction of reservoir, if it is sufficient to overcome the strength of rock. The strain can have a large impact on the microstructures and alters the petrophysical properties of the reservoir rock. The most common petrophysical properties are porosity and permeability, which are affected by the change in net stress (Dautriat et al., 2007). Many researches have been done to show the impact of net stress on the porosity and permeability of the reservoirs. In most researches, with increase of net stress, the permeability reduces because of rock compaction (David et al. 1994). However, in some cases with an increase the net stress, permeability 
increases because of the stress paths (Rhett, 1992).

Permeability is one of the fundamental physical properties of rocks which uses to transport hydrocarbons (Lim \& Kim, 2004). This property can indicate different behaviors, such as permeability hysteresis behavior (Teklu et al., 2016), stress-dependent permeability (Dautriat et al., 2007), and straindependent permeability (Shin et al., 2014) which can play a key role in the productivity of wells during the depletion of the reservoir. Teklu et al. (2016) expressed that permeability shows hysteresis behavior, which permeability decreases with increasing net stress in both consolidated and unconsolidated porous media and increases with decreasing net stress. Stress-dependent permeability has been noticed by production engineers in oil industry, which the pressure depletion can alter the net stress that can cause the change of permeability (Yale \& Crawford, 1998; Han \& Dusseault, 2003). Shin et al. (2014) presented that permeability behaves as the strain-dependent permeability, which the quantity of permeability can change with the variation of strain.

Permeability evolution models have been studied by several researchers in terms of porosity, stress, strain, etc (Morris et al., 2003; Ma, 2015). Previous studies such as Shin et al. (2014) showed that permeability is indirectly related to the porosity, pore size distribution, and pore architecture of the porous media. These parameters can be altered when a strain field is imposed on the porous media. Then, due to the strain-dependent porosity and the direct relation of porosity with both deformation and pore pressure, the 
permeability evolution model based on porosity is selected in order to present strain-dependent permeability. The relation between permeability and porosity is usually investigated based on the laboratory experiments, and quite a few theories have been proposed to express this relation (Schutjens et al. 2004).

To understand the effect of strain-dependent permeability on hydrocarbon production, the coupled reservoir geomechanical modelling is required. Previous studies emphasized that they are a remarkable difference in reservoir response during production between uncoupled reservoir simulations and coupled reservoir simulator with elastic deformation (Yale et al., 2000) and plastic deformation (Yale, 2002). Originally, the coupled fluid flow and deformation in porous media was first described by Terzaghi (1925) with proposing the concept of effective stress for incompressible solid grains. Later, the extension of the Terzaghi's work to the three-dimensional was formulated by Biot (1941b a). Subsequently, the development of poroelasticity theory for anisotropic materials and its extension to poro-elastoplasticity was developed by (Biot, 1955, 1962, Coussy, 1995). In recent years, several researchers have been published in porous media to find coupled geomechanics and reservoir flow such as, Phillips \& Wheeler (2007); Wei \& Zhang (2010); Sanei et al. (2017); Jiang \& Yang (2018); Duŕan et al. (2019).

There are four methods that are currently employed in the coupling reservoir and geomechanics: full coupled, iterative coupled, loose coupled, and explicit coupled (Settari \& Walters, 2001; Dean et al., 2006). In the full coupled 
scheme, the governing equations of reservoir and rock deformation are solved simultaneously at every time step. This method is unconditionally stable but it is computationally expensive Gutierrez \& Lewis, 2002, Pan et al. 2009). In the iterative coupled scheme, there exit different types depending on which variables are kept constant. For instance, by fixing the variation of total volumetric stress for reservoir equations and the fluid pressure for geomechanics, one solves the flow problem first, and then uses computed pressure approximation to solve the deformation problem. This method is iterated until the solution converges to the desired tolerance (Tran et al. 2005; Wheeler \& Gai, 2007). In the loose coupled scheme, the coupling between reservoir and geomechanics is solved only after a certain number of flow time steps and it is only conditionally stable (Minkoff et al., 2003). The explicit coupled scheme is a special case of the iterative coupled method, where only one iteration is taken and it is only conditionally stable (Park, 1983; Armero, 1999). Due to the high computational cost of the full coupled scheme, it is desirable to develop iterative solution schemes that can be competitive with the fully coupled approach. Kim et al. (2011a b) proposed four types of iterative coupled procedures, such as drained split, undrained split, fixed strain split, and fixed stress split. Kim et al. (2011c) concluded that among iterative schemes, the fixed stress split strategy is unconditionally stable and has better convergence properties.

In this article, the strain-dependent permeability is analyzed using coupled reservoir geomechanical modeling. To develop the coupled reservoir and 
geomechanics, a fixed stress iterative coupled scheme is used. To represent fluid flow, the conservation of mass and Darcy's law by considering nonlinear permeability models are employed. To define the rock deformation, the conservation of momentum, Biot's law and DiMaggio-Sandler elastoplastic model are used. The numerical approximation is done by a mixed finite element for pore pressure and a continuous Galerkin finite element for displacement. Solutions from this coupling have been verified using analytical solutions and also experimental test data. The implementation of this study is done using the NeoPZ library, which is an object-oriented scientific computational environment, providing a framework for developing finite element schemes (Devloo, 1997, 2000).

\section{Model Formulation}

The governing equations for coupled reservoir geomechanical modeling are combined for a set of conservation laws and constitutive laws. The conservation equations are: mass and momentum.

\subsection{Mass Conservation}

For a slightly compressible fluid, the mass conservation is presented as (Rudnicki, 1986):

$$
\frac{\partial\left(m_{f}\right)}{\partial t}+\operatorname{div}(\mathbf{q})=0
$$


where $m_{f}$ is the fluid content $\left[\mathrm{kg} \mathrm{m}^{-3}\right], \mathbf{q}=\rho_{f} \mathbf{v}_{f}$ is the flux $\left[\mathrm{kg} \mathrm{s}^{-1} \mathrm{~m}^{-2}\right]$, and $\mathbf{v}_{f}\left[\mathrm{~m} \mathrm{~s}^{-1}\right]$ is the fluid velocity. The corresponding initial and boundary conditions of mass conservation are:

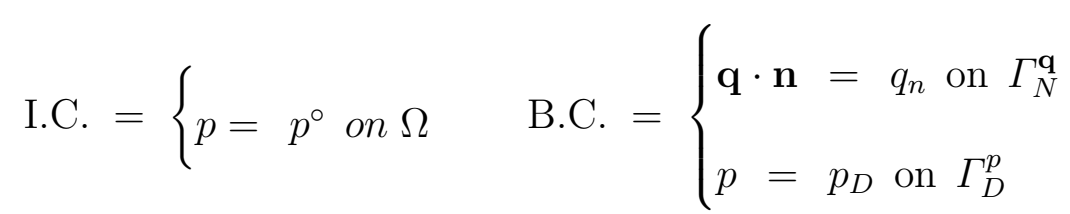

The fluid velocity in equation (1) is defined by the Darcy's law, as:

$$
\mathbf{v}_{f}=-\frac{\mathbf{K}}{\eta} \nabla p
$$

where $\eta$ is the fluid dynamic viscosity $[\mathrm{Pas}], \mathbf{K}$ is the absolute permeability tensor $\left[\mathrm{m}^{-2}\right]$. The absolute permeability is considered isotropic and described in terms of a scalar value $\kappa\left[\mathrm{m}^{-2}\right]$, as:

$$
\mathbf{K}=\kappa I
$$

The total fluid content in equation (1) is expressed by:

$$
m_{f}=\phi \rho_{f}
$$

The equation (5) can be linearized using the expression for the Lagrangian porosity. Without loss of generality the porosity change $\delta \phi$ can be decomposed in two parts $\delta \phi=\phi-\phi^{\circ}$ as (Kim et al. , 2011b): 


$$
\begin{cases}\delta \phi & =\delta \phi_{\text {matrix }}+\delta \phi_{\text {pore }} \\ \delta \phi_{\text {matrix }} & =\alpha\left(\epsilon_{e v}-\epsilon_{e v}^{\circ}\right)+\phi_{p}-\phi_{p}^{\circ} \\ \delta \phi_{\text {pore }} & =S\left(p-p^{\circ}\right)\end{cases}
$$

The Lagrangian porosity is defined as follows (Kim et al., 2011b; Coussy, 2004):

$$
\phi=\phi^{\circ}+\alpha\left(\epsilon_{e v}-\epsilon_{e v}^{\circ}\right)+\phi_{p}-\phi_{p}^{\circ}+S\left(p-p^{\circ}\right)
$$

where $S=\left((1-\alpha)\left(\alpha-\phi^{\circ}\right)\right) / K_{d r}$, in which $K_{d r}[\mathrm{MPa}]$ is the elastic rock bulk modulus in drained conditions. $\phi_{p}$ is the plastic porosity and written as:

$$
\phi_{p}=\alpha_{p} \epsilon_{p v}
$$

where $\epsilon_{p v}$ is the plastic volumetric strain. The parameter $\alpha_{p}$ is the nonlinear Biot's coefficient and shares the same restrictions of Biot's coefficient $\alpha$, i.e. $\phi^{\circ} \leq \alpha_{p} \leq 1$ (Coussy, 2004, Bui et al., 2016, da Silva et al., 2018). There are experimental results that support the fact that $\alpha \neq \alpha_{p}$ (Xie \& Shao, 2015). However, some researchers (Zhou et al., 2008, Kim et al. 2011b c) assume that $\alpha=\alpha_{p}$. In this research, for simplicity $\alpha=\alpha_{p}$ is considered. The volumetric elastic strain $\epsilon_{e v}$ can be related to volumetric total stress $\sigma_{t v}=\operatorname{tr}\left(\boldsymbol{\sigma}_{t}\right) / 3$ as follows: 


$$
\left(\sigma_{t v}-\sigma_{t v}^{\circ}\right)+\alpha\left(p-p^{\circ}\right)=K_{d r}\left(\epsilon_{e v}-\epsilon_{e v}^{\circ}\right)
$$

By inserting equation (9) into equation (7) and considering $S_{e}=S+\phi^{\circ} c_{f}$, an alternative expression for $\left(\phi \rho_{f}\right)$ is obtained as (Kim et al., 2012; Duŕan et al., 2019):

$$
\phi \rho_{f}=\rho_{f}^{\circ}\left(\phi^{\circ}+\frac{\alpha}{K_{d r}}\left(\sigma_{t v}-\sigma_{t v}^{\circ}\right)+\phi_{p}-\phi_{p}^{\circ}+\left(S_{e}+\frac{\alpha^{2}}{K_{d r}}\right)\left(p-p^{\circ}\right)\right)
$$

where $S_{e}$ is the inverse of Biot's modulus $M[\mathrm{MPa}], c_{f}$ is the fluid compressibility. $\quad \rho_{f}^{\circ}$ and $\rho_{f}$ are the initial and current fluid density $\left[\mathrm{kg} \mathrm{m}^{-3}\right]$, respectively. $\sigma_{t v}^{\circ}$ and $\sigma_{t v}$ are the initial and current volumetric total stress [MPa], respectively.

\subsection{Momentum Conservation}

The conservation of momentum under the quasi-static assumption is expressed as (Rudnicki, 1986):

$$
\operatorname{div}\left(\boldsymbol{\sigma}_{t}-\boldsymbol{\sigma}_{t}^{\circ}\right)=0
$$

where $\operatorname{div}(\cdot)\left[\mathrm{m}^{-1}\right]$ is the divergence operator on the deform configuration. $\boldsymbol{\sigma}_{t}^{\circ}$ and $\boldsymbol{\sigma}_{t}[\mathrm{MPa}]$ are the initial and the current Cauchy total stress tensor, respectively. The corresponding initial (referred with the superscript $(\cdot)^{\circ}$ ) and boundary conditions of momentum conservation are: 


$$
\text { I.C. }=\left\{\begin{array}{ll}
p= & p^{\circ} \text { on } \Omega \\
\mathbf{u}= & \mathbf{u}^{\circ} \text { on } \Omega
\end{array} \quad \text { B.C. }= \begin{cases}\boldsymbol{\sigma}_{t} \cdot \mathbf{n}=\mathbf{t} \text { on } \Gamma_{N}^{\sigma_{t}} \\
\mathbf{u}=\mathbf{u}_{D} \text { on } \Gamma_{D}^{\mathbf{u}}\end{cases}\right.
$$

The momentum conservation in equation (11) can be expressed in terms of Cauchy effective stress tensor as follows:

$$
\operatorname{div}\left(\boldsymbol{\sigma}-\boldsymbol{\sigma}^{\circ}-\alpha\left(p-p^{\circ}\right) \mathbf{I}\right)=0
$$

where $\mathbf{I}$ is the second rank identity tensor. $p^{\circ}$ and $p$ are the initial and current fluid pressure $[\mathrm{MPa}]$, respectively. $\boldsymbol{\sigma}^{\circ}$ and $\boldsymbol{\sigma}$ are the initial and current Cauchy effective stress [MPa], respectively. The effective stress $\boldsymbol{\sigma}$ is determined by linear stress-strain relationship, as:

$$
\boldsymbol{\sigma}-\boldsymbol{\sigma}^{\circ}=2 \mu\left(\boldsymbol{\epsilon}_{e}-\boldsymbol{\epsilon}_{e}^{\circ}\right)+\lambda \operatorname{tr}\left(\boldsymbol{\epsilon}_{e}-\boldsymbol{\epsilon}_{e}^{\circ}\right) \mathbf{I}
$$

where $\boldsymbol{\epsilon}_{e}$ is the elastic strain. The parameters $\mu$ and $\lambda$ are the Lamé constants $[\mathrm{MPa}]$.

\subsection{Elastoplastic Constitutive Models}

Nonlinear elastoplastic model is defined by the theory of elastoplasticity, when a material undergoes an irreversible deformations. The total strain tensor $\boldsymbol{\epsilon}$ is decomposed into two components as follows de Souza Neto et al. 2008): 


$$
\boldsymbol{\epsilon}=\boldsymbol{\epsilon}_{e}+\boldsymbol{\epsilon}_{p}
$$

where $\boldsymbol{\epsilon}_{e}$ is the elastic strain component and $\boldsymbol{\epsilon}_{p}$ is the plastic strain component. The elastic component is reversible and the plastic component represents a permanent deformation (de Souza Neto et al., 2008). The total strain is defined in terms of displacement $\mathbf{u}$ as:

$$
\boldsymbol{\epsilon}=\frac{1}{2}\left(\nabla \mathbf{u}+\nabla^{T} \mathbf{u}\right)
$$

The elastoplastic deformation is mathematically described by four fundamental axioms as follows (de Souza Neto et al. 2008):

Elastic law. The elastic law can be defined by using the linear stress-strain relationship expressed by equation (14).

Yield criterion. Describes the elastic limit and the plastic part through a plasticity yield function $\Phi=\Phi(\boldsymbol{\sigma}, \mathbf{A})$, where $\mathbf{A}=\bar{\rho} \partial \mathbf{F}^{p} / \partial \chi$ is the hardening thermodynamic force, $\mathbf{F}^{p}$ is the plastic part of Helmholtz free energy $\mathbf{F}$, and $\chi$ is the hardening variable. The plasticity function assumes negative values in the elastic part and null values in the plastic part (Kossa, 2011).

Flow rule. Assumes the existence of a plastic potential function $\Psi=\Psi(\boldsymbol{\sigma}, \mathbf{A})$, which specifies how the plastic deformation tensor evolves in the plasticity process $\dot{\epsilon}_{p}=\dot{\gamma} \mathbf{N}$, in which $\mathbf{N}(\boldsymbol{\sigma}, \mathbf{A})=\partial \Psi / \partial \boldsymbol{\sigma}$ is the flow direction 
and $\dot{\gamma}$ is the plastic multiplier. The flow rule is called associative if the plastic potential function equals to yield function, namely $\Psi=\Phi$ (Davis \& Selvadurai, 2002).

Hardening law. Specifies how the internal damage variable $\dot{\chi}=\dot{\gamma} H$ evolves, in which, $H(\boldsymbol{\sigma}, \mathbf{A})=-\partial \Psi / \partial \mathbf{A}$ is the hardening modulus.

\subsubsection{Numerical integration algorithm for the elastoplastic model}

The numerical integration is divided into two main steps: the elastic trial step and the plastic corrector step (or return-mapping algorithm). If the elastic trial state lies within the elastic domain or on the yield surface, the solution is accepted. Otherwise, if the trial stress in the first step fails to verify the plastic admissible condition, it is projected onto the yield surface by the return-mapping algorithm (de Souza Neto et al., 2008).

The incremental constitutive model is formed by giving the elastic strain $\boldsymbol{\epsilon}_{e}^{n-1}$, the plastic strain $\boldsymbol{\epsilon}_{p}^{n-1}$, and the hardening variable $\chi^{n-1}$ at a (pseudo) time step $t^{n-1}$, and also given a prescribed incremental strain tensor $\Delta \boldsymbol{\epsilon}$ for the time interval $\left[t^{n-1}, t^{n}\right]$ in order to find the following system of algebraic equations at a time-step $t^{n}$ de Souza Neto et al., 2008):

$$
\begin{aligned}
\boldsymbol{\epsilon}_{e}^{n} & =\boldsymbol{\epsilon}_{e}^{n-1}+\Delta \boldsymbol{\epsilon}-\Delta \gamma \boldsymbol{N}\left(\boldsymbol{\sigma}^{n}, \mathbf{A}^{n}\right) \\
\chi^{n} & =\chi^{n-1}+\Delta \gamma H\left(\boldsymbol{\sigma}^{n}, \mathbf{A}^{n}\right)
\end{aligned}
$$

for the unknowns $\boldsymbol{\epsilon}_{e}^{n}, \chi^{n}$ and incremental of plastic multiplier $\Delta \gamma$, it is subjected to the restrictions: 


$$
\Delta \gamma \geq 0, \Phi\left(\boldsymbol{\sigma}^{n}, \mathbf{A}^{n}\right) \leq 0, \Delta \gamma \Phi\left(\boldsymbol{\sigma}^{n}, \mathbf{A}^{n}\right)=0
$$

Solving the elastoplastic problem occurs in two steps. First an elastic response is computed (i.e. elastic trial step), where $\Delta \gamma=0$ leading to the elastic trial stress $\boldsymbol{\epsilon}_{e_{\text {trial }}}^{n}=\boldsymbol{\epsilon}_{e}^{n-1}+\Delta \boldsymbol{\epsilon}$ and hardening variable $\chi_{\text {trial }}^{n}=\chi^{n-1}$. Next, $\boldsymbol{\sigma}_{\text {trial }}^{n}$ and $\Phi\left(\boldsymbol{\sigma}_{\text {trial }}^{n}, \mathbf{A}_{\text {trial }}^{n}\right)$ are computed as a function of $\boldsymbol{\epsilon}_{e_{\text {trial }}^{n}}^{n}$. If $\Phi\left(\boldsymbol{\sigma}_{\text {trial }}^{n}, \mathbf{A}_{\text {trial }}^{n}\right) \leq 0$, the elastic response is a valid solution and the elasto plastic variables are updated from the trial values $(\cdot)^{n}:=(\cdot)_{\text {trial }}^{n}$. Otherwise, the return-mapping algorithm is applied and a set of nonlinear equations needs to be solved (de Souza Neto et al. 2008):

$$
\begin{gathered}
\boldsymbol{\epsilon}_{e}^{n}=\boldsymbol{\epsilon}_{e_{\text {trial }}}^{n}-\Delta \gamma \boldsymbol{N}\left(\boldsymbol{\sigma}^{n}, \mathbf{A}^{n}\right) \\
\chi^{n}=\chi_{\text {trial }}^{n}+\Delta \gamma H\left(\boldsymbol{\sigma}^{n}, \mathbf{A}^{n}\right) \\
\Delta \gamma>0, \Phi\left(\boldsymbol{\sigma}^{n}, \mathbf{A}^{n}\right)=0
\end{gathered}
$$

Once the solution $\boldsymbol{\epsilon}_{e}^{n}$ has been calculated, the plastic strain at a time step $t^{n}$ can be computed as:

$$
\boldsymbol{\epsilon}_{p}^{n}=\boldsymbol{\epsilon}_{p}^{n-1}+\Delta \boldsymbol{\epsilon}-\Delta \boldsymbol{\epsilon}_{e}
$$

\subsubsection{DiMaggio-Sandler Elastoplasticity Model}

The original DiMaggio-Sandler elastoplasticity model was presented in (DiMaggio \& Sandler, 1971). It was initially applied for granular soils, and currently is used in the oil industry to present the behavior of rocks at depth 
(Cecílio et al. 2015). The yield function $\Phi$ of DiMaggio-Sandler model is defined by a failure function $F_{f}\left(I_{1}, \sqrt{J_{2}}, \beta\right)$, and a cap function $F_{c}\left(I_{1}, \sqrt{J_{2}}, L, \beta\right)$, as follows:

$$
\Phi=\left\{\begin{array}{cc}
F_{f}\left(I_{1}, \sqrt{J_{2}}, \beta\right), & I_{1}>L \\
F_{c}\left(I_{1}, \sqrt{J_{2}}, L, \beta\right), & L \geqslant I_{1} \geqslant X
\end{array}\right.
$$

where $\beta$ is the Lode angle $\left[^{\circ}\right], L(\chi)$ is the cap position parameter [MPa], $X(\chi)$ is the current cap surface position $[\mathrm{MPa}], I_{1}$ is the first invariant of the stress tensor [MPa], and $J_{2}$ is the second deviatoric stress tensor [ $\left.\mathrm{MPa}^{2}\right]$. A typical $2 D$ profile of DiMaggio-Sandler yield surface is plotted in Fig. 1 (left).

$$
\left\{\begin{array}{l}
F_{f}\left(I_{1}, \sqrt{J_{2}}, \beta\right)=\sqrt{J_{2}}-\frac{F_{s}\left(I_{1}\right)}{\Gamma(\beta)} \\
F_{c}\left(I_{1}, \sqrt{J_{2}}, L, \beta\right)=\left(\frac{I_{1}-L}{R F_{s}(L)}\right)^{2}+\left(\frac{\sqrt{J_{2}} \Gamma(\beta)}{F_{s}(L)}\right)^{2}-1
\end{array}\right.
$$

with,

$$
\begin{aligned}
& L(\chi)=\left\{\begin{array}{lll}
\chi & \text { if } & \chi<0 \\
0 & \text { if } \quad & \chi \geq 0
\end{array}\right. \\
& F_{s}(\iota)=A-C \exp (B \iota) \\
& X \quad=L-R F_{s}(L)
\end{aligned}
$$


where $A[\mathrm{MPa}], B\left[\mathrm{MPa}^{-1}\right], C[\mathrm{MPa}]$ are material property constants and $R$ is the ratio of principal ellipse radii of the cap surface, and the factor $\Gamma(\beta)$ is given by:

$$
\Gamma(\beta)=\frac{1}{2}\left[(1+\sin (3 \beta))+\frac{1}{\psi}(1-\sin (3 \beta))\right]
$$

where, $\psi$ has the range from $7 / 9$ to $9 / 7$, as shown in Fig. 1 (right). The original DiMaggio-Sandler model refers to $\psi=1$, such that $\Gamma(\beta)=1$.

The hardening parameter $\chi$ of DiMaggio-Sandler cap model is defined through a functional of $X(\chi)$ and volumetric plastic strain $\epsilon_{p v}$ as follows (Fossum et al., 1995):

$$
\epsilon_{p v}=W\left(\exp \left[D\left(X-X_{\circ}\right)\right]-1\right)
$$

where $X_{\circ}$ is the initial cap position $[\mathrm{MPa}] . D\left[\mathrm{MPa}^{-1}\right]$ and $W$ are the material properties constants.

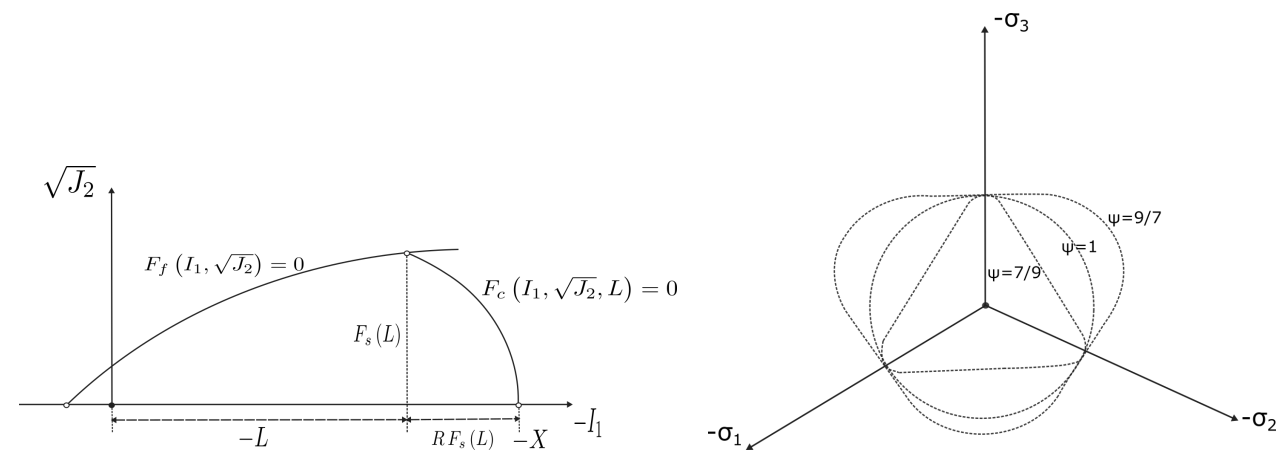

Figure 1. (left) DiMaggio-Sandler plastic yield profile in the $\left(I_{1}, \sqrt{J_{2}}\right)$ plane (Sandler \& Rubin 1979), (right) yield surface cross section of DiMaggio-Sandler model for $\psi=7 / 9$, $\psi=1, \psi=9 / 7$ (Cecílio et al. 2015). 


\subsection{Strong Statement of Coupled Reservoir Geomechanics}

The strong statement of the coupled reservoir geomechanics is presented using the conservation laws given in equations (1) and (13), as follows:

$$
\left\{\begin{array}{l}
\operatorname{div}\left(\boldsymbol{\sigma}-\boldsymbol{\sigma}^{\circ}-\alpha\left(p-p^{\circ}\right) \mathbf{I}\right)=0 \\
\frac{\partial\left(m_{f}\right)}{\partial t}+\operatorname{div}(\mathbf{q})=0
\end{array}\right.
$$

It is completed by considering the equations (3) and (14), namely:

$$
\left\{\begin{array}{l}
\boldsymbol{\sigma}-\boldsymbol{\sigma}^{\circ}=2 \mu\left(\boldsymbol{\epsilon}_{e}-\boldsymbol{\epsilon}_{e}^{\circ}\right)+\lambda \operatorname{tr}\left(\boldsymbol{\epsilon}_{e}-\boldsymbol{\epsilon}_{e}^{\circ}\right) \mathbf{I} \\
\mathbf{v}_{f}=-\frac{\mathbf{K}}{\eta} \nabla p
\end{array}\right.
$$

The strong statement is incorporated with Dirichlet and Neumann boundary conditions in the equations (2) and (12).

\subsection{Weak Statement of Coupled Reservoir Geomechanics}

The weak statement of the coupled reservoir geomechanics is presented by using one field $\mathbf{u}$ as state variable for the geomechanics problem and two fields $\mathbf{q}$ and $p$ for the reservoir flow problem, as: 


$$
\left\{\begin{array}{l}
\int_{\Omega}\left(\boldsymbol{\sigma}^{n}-\boldsymbol{\sigma}^{\circ}-\alpha\left(p^{n}-p^{\circ}\right) \mathbf{I}\right) \cdot \boldsymbol{\epsilon}\left(\boldsymbol{\phi}_{u}\right) d \Omega-\int_{\Gamma_{N}}\left(\mathbf{t}^{n}-\mathbf{t}^{\circ}\right) \cdot \boldsymbol{\phi}_{u} d \Gamma=0 \\
\int_{\Omega}\left(\rho_{f}^{n} \frac{\kappa^{n} \mathbf{I}}{\eta}\right)^{-1} \mathbf{q}^{n} \cdot \boldsymbol{\phi}_{q} d \Omega+\int_{\Gamma_{D}} p^{n} \cdot \boldsymbol{\phi}_{q} \cdot \mathbf{n} d \Gamma-\int_{\Omega} p^{n} \cdot \operatorname{div}\left(\boldsymbol{\phi}_{q}\right) d \Omega=0 \\
\int_{\Omega} \operatorname{div}\left(\mathbf{q}^{n}\right) \cdot \phi_{p} d \Omega+\int_{\Omega}\left(\frac{\left.\phi \rho_{f}\right|^{n}-\left.\phi \rho_{f}\right|^{n-1}}{\delta t}\right) \cdot \phi_{p} d \Omega=0
\end{array}\right.
$$

where $\Omega$ is the domain, $\Gamma$ is the boundary and $\phi_{u}, \phi_{q}, \phi_{p}$ are the test functions. The weak statement is incorporated with Dirichlet and Neumann boundary conditions in the equations $(2)$ and $(12)$.

\subsection{Iterative Coupled Scheme}

The fixed stress iterative coupled scheme is as a robust method to approximate solutions of nonlinear equations. The schematic of the solution procedures by using the fixed-stress splits is illustrated in the Figure 2. The iterative coupled scheme computes a new state $(\mathbf{u}, \mathbf{q}, p)^{m}$ in a time step of size $\Delta t$, by applying an external loop with counter $m \rightarrow 1$ to execute a sequence of two nonlinear solvers (a reservoir module and a geomechanics module with internal loops that counter $n$ ). 


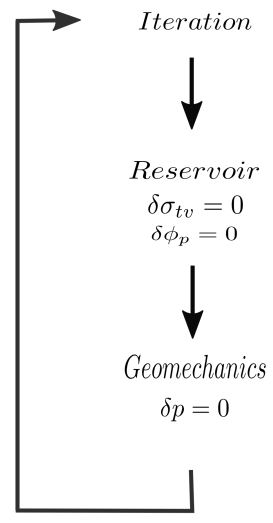

Figure 2. Iterative coupled scheme with fixed-stress split (Kim, 2010).

In order to describe the implementation of iterative coupled scheme, the change in porosity in equation (6) is rewritten as:

$$
\begin{gathered}
\phi=\phi^{\circ}+\delta \phi \\
\delta \phi=\delta \phi_{\text {pore }}+\overbrace{\delta \phi_{\text {matrix }}}^{\delta \phi_{r}^{*}+\delta \phi_{g}^{*}} \\
\delta \phi=\delta \phi_{\text {pore }}+\delta \phi_{r}^{*}+\delta \phi_{g}^{*}
\end{gathered}
$$

where

$$
\left\{\begin{array}{l}
\delta \phi_{\text {pore }}=S\left(p-p^{\circ}\right) \\
\delta \phi_{\text {matrix }}=\underbrace{\frac{\alpha^{2}}{K_{d r}}\left(p-p^{\circ}\right)}_{\delta \phi_{r}^{*}}+\underbrace{\frac{\alpha}{K_{d r}}\left(\sigma_{t v}-\sigma_{t v}^{\circ}\right)+\phi_{p}-\phi_{p}^{\circ}}_{\delta \phi_{g}^{*}}
\end{array}\right.
$$

where $\delta \phi_{r}^{*}$ and $\delta \phi_{g}^{*}$ are the matrix parts of porosity change. The variation of the fluid content expressed by equations 10 and 32 is computed using 
two stages (Settari \& Mourits, 1998; Mikelić \& Wheeler, 2012; Duŕan et al., 2019):

1. For the reservoir module the variation of $\delta \phi_{\text {pore }}$ and $\delta \phi_{r}^{*}$ are computed and the $\delta \phi_{g}^{*}$ is considered constant;

2. For the geomechanics module $\delta \phi_{g}^{*}$ is updated.

At the first step, it is set to $\delta \phi_{g}^{* m-1} \rightarrow 0$ and add the $\left(\alpha^{n-1}\right)^{2} / K_{d r}$ to the reservoir module, and the equation is solved as follows:

- Reservoir Module: by allowing to compute implicitly $p^{n, m}$, while the total volumetric stress and the plastic porosity are constant during solving the reservoir flow iterations, the porosity $\phi^{n, m}$ is approximated as:

$$
\left\{\begin{array}{l}
\phi^{n, m} \approx \phi^{\circ}+\delta \phi_{\text {pore }}^{n, m}+\delta \phi_{r}^{* n-1, m}+\delta \phi_{g}^{* m-1} \\
\phi^{n, m} \approx \phi^{\circ}+\underbrace{S\left(p^{n, m}-p^{\circ}\right)}_{\delta \phi_{\text {pore }}}+\underbrace{\left(\left(\alpha^{n-1}\right)^{2} / K_{d r}\right)\left(p^{n, m}-p^{\circ}\right)}_{\delta \phi_{r}^{*}}+\underbrace{\delta \phi_{g}^{* m-1}}_{\delta \phi_{g}^{*}}
\end{array}\right.
$$

Consecutively, the pressure is transferred to the geomechanics module and the equation is solved as follows:

- Geomechanics Module: Once the pressure $p^{n, m}$ is determined, then 
the term $\delta \phi_{g}^{* m}$ is computed implicitly using the expression:

$$
\delta \phi_{g}^{* m}=\frac{\left(\alpha^{n-1}\right)^{2}}{K_{d r}}\left(\sigma_{t v}^{n, m}-\sigma_{t v}^{\circ}\right)+\phi_{p}^{n, m}-\phi_{p}^{\circ}
$$

It is considered to maintain the Biot coefficient constant during a timestep iteration and only between timesteps is updated using the following expression (Kim et al., 2012):

$$
\alpha=1-\frac{K_{d r_{e p}}}{K_{s}} \quad ; \quad K_{d r_{e p}}=\frac{\delta \sigma_{v}}{\delta \epsilon_{v}}
$$

where $K_{d r_{e p}}[\mathrm{MPa}]$ is the elastoplastic tangent bulk modulus, $K_{s}[\mathrm{MPa}]$ is the solid bulk modulus, $\delta \sigma_{v}[\mathrm{MPa}]$ is volumetric effective stress variation, and $\delta \epsilon_{v}$ is the volumetric total strain variation.

The iteration between both reservoir and geomechanics module is repeated until a desired stopping criteria is reached.

\section{Permeability evolution models}

To be able to describe the strain-dependent permeability properly, it is required to review the available permeability models, in order to choose an appropriate one. Permeability evolution models have been studied by several researchers in terms of porosity, stress, strain, temperature, chemical process, etc. (Zhu \& fong Wong, 1997, Morris et al., 2003, Ma, 2015). Generally, there are three main types of permeability evolution models under mechanical condition in porous media, i.e. based on (i) porosity, (ii) stress, and (iii) 
strain, that can be applied to specific conditions. The purpose of this section is to review the permeability models and choose the suitable ones.

\subsection{Permeability evolution models based on porosity}

Several semi-empirical equations have been proposed to estimate rock permeability $\kappa$ based on the porosity $\phi$. The Table 1 summarizes some permeability-porosity models found in the literature.

Table 1. Permeability-porosity models (Kozeny, 1927, Carman, 1937, Walsh \& Brace, 1984; Costa, 2006; Petunin et al., 2011, Nelson, 1994| Davies \& Davies, 1999).

\begin{tabular}{|l|l|l|}
\hline Model & Formulation & Comments \\
\hline \hline Kozeny-Carman & $\kappa=\frac{\phi^{3}}{B_{c} \tau_{c}^{2} S_{c}^{2}}$ & $\begin{array}{l}S_{c}\left[\mathrm{~m}^{-1}\right] \text { is specific surface area, } \tau_{c} \text { is } \\
\text { tortuosity, } B_{c} \text { is pore shape coefficient. }\end{array}$ \\
\hline Costa & $\kappa=\varrho_{c} \frac{\phi^{Z_{c}}}{1-\phi}$ & $\varrho_{c}$ and $\mathcal{Z}_{c}$ are the constant coefficient. \\
\hline Petunin & $\frac{\kappa}{\kappa^{\circ}}=\left(\frac{\phi}{\phi^{\circ}}\right)^{Z_{g}}$ & $\mathcal{Z}_{g}$ is the constant coefficient. \\
\hline Nelson & $\log _{10}(\kappa)=\mathcal{Z}_{n} \phi+\varrho_{n}$ & $\mathcal{Z}_{n}$ and $\varrho_{n}$ are the constant coefficient. \\
\hline Davies & $\kappa=\kappa^{\circ} \exp \left(\mathcal{Z}_{d}\left(\frac{\phi}{\phi^{\circ}}-1\right)\right)$ & $\mathcal{Z}_{d}$ is the constant coefficient. \\
\hline
\end{tabular}

\subsection{Permeability evolution models based on stress}

Many studies have been done to investigate a relationship between permeability $\kappa$ and stress $\sigma$ in porous media. The Table 2 summarizes some permeability-stress models found in the literature.

Table 2. Permeability-stress models (Ghabezloo et al. 2009, Zhou et al., 2011, David et al., 1994; Xu et al., 2008; Raghavan \& Chin, 2004).

\begin{tabular}{|l|l|l|}
\hline Model & Formulation & Comments \\
\hline \hline Ghabezloo & $\kappa=a_{g} \sigma_{a}^{b_{g}}$ & $\begin{array}{l}\sigma_{a} \text { is the axial effective stress, } a_{g} \text { and } b_{g} \\
\text { are the constant coefficient. }\end{array}$ \\
\hline Zhou & $\kappa=a_{z}-b_{z} \ln \left(\sigma_{a}\right)$ & $a_{z}$ and $b_{z}$ are the constant coefficient. \\
\hline David or $\mathrm{Xu}$ & $\kappa=\kappa^{\circ} \exp \left(a_{d}\left(\sigma_{a}-\sigma_{a}^{\circ}\right)\right)$ & $a_{d}$ is the constant coefficient. \\
\hline Raghavan & $\kappa=\kappa^{\circ} \exp \left(a_{r}\left(\sigma_{m}\right)\right)$ & $\begin{array}{l}\sigma_{m} \text { is the effective mean stress, } a_{r} \text { is the } \\
\text { constant coefficient. }\end{array}$ \\
\hline
\end{tabular}




\subsection{Permeability evolution models based on strain}

Few researches have been published to show the relation between permeability $\kappa$ and strain $\epsilon$ in porous media. The Table 3 summarizes some permeability-strain models found in the literature.

Table 3. Permeability-strain models (Main et al. 2000, Minkoff et al. 2003, Ni et al., 2018).

\begin{tabular}{|l|l|l|}
\hline Model & Formulation & Comments \\
\hline \hline Main & $\kappa=\kappa_{0} \exp \left[a_{m_{n}}\left(\epsilon_{a}-\epsilon_{a}^{\circ}\right)\right]$ & $\begin{array}{l}\epsilon_{a}^{\circ} \text { and } \epsilon_{a} \text { are the initial and current axial } \\
\text { strain, } a_{m_{n}} \text { is the constant coefficient. }\end{array}$ \\
\hline Minkoff or Ni & $\kappa=a_{m} \exp \left(b_{m}\left(\epsilon_{v}\right)\right)$ & $\begin{array}{l}\epsilon_{v} \text { is the volumetric strain, } a_{m} \text { and } b_{m} \text { are } \\
\text { the constant coefficient. }\end{array}$ \\
\hline
\end{tabular}

\section{Strain-dependent permeability models}

During the depletion of hydrocarbon reservoirs, porosity and permeability may change in response to an increase of the effective stress, which can alter the pore geometry of the reservoir rock (Zimmerman, 1991; Schatz et al., 1982). The variation of pore volume due to increase effective stress has an impact on both porosity and permeability (Santos et al., 2014). In addition, previous studies such as Shin et al. (2014) showed that permeability is indirectly related to the porosity, pore size distribution, and pore architecture of the porous media. These parameters are induced when a strain field is imposed on the porous media. Then, due to the strain-dependent porosity and the direct relation of porosity with both deformation and pore pressure, the permeability evolution model based on porosity is selected in order to present strain-dependent permeability. In this study, various permeability- 
porosity models (reported in Table 1) are used and modified to consider the initial permeability $\kappa^{\circ}$ and porosity $\phi^{\circ}$ which are given in Table 4.

Table 4. The modified permeability-porosity models (Costa, 2006, Petunin et al., 2011. Nelson, 1994, Davies \& Davies, 1999).

\begin{tabular}{|l|l|l|}
\hline Model & Formulation & Comments \\
\hline \hline Costa & $\frac{\kappa}{\kappa^{\circ}}=\varrho\left(\frac{1-\phi^{\circ}}{1-\phi}\right)\left(\frac{\phi}{\phi^{\circ}}\right)^{\mathcal{Z}}$ & $\varrho$ and $\mathcal{Z}$ are the constant coefficient. \\
\hline Petunin & $\frac{\kappa}{\kappa^{\circ}}=\left(\frac{\phi}{\phi^{\circ}}\right)$ & $\mathcal{Z}$ is the constant coefficient. \\
\hline Nelson & $\log _{10}\left(\frac{\kappa}{\kappa^{\circ}}\right)=\mathcal{Z}\left(\phi-\phi^{\circ}\right)+\varrho$ & $\mathcal{Z}$ and $\varrho$ are the constant coefficient. \\
\hline Davies & $\kappa=\kappa^{\circ} \exp \left(\mathcal{Z}\left(\frac{\phi}{\phi^{\circ}}-1\right)\right)$ & $\mathcal{Z}$ is the constant coefficient. \\
\hline
\end{tabular}

\section{Numerical Model Verification}

Numerical implementation of the iterative coupled scheme is accomplished through the finite element method. Several numerical examples are done to verify the iterative coupled reservoir geomechanical modeling. They are included: a comparison between experimental data and numerical results for DiMaggio-Sandler plasticity model, a comparison between analytical solution and numerical results of a vertical wellbore for a linear case, and a comparison between reference solution and numerical results of a vertical wellbore for a nonlinear case.

\subsection{Implementation of DiMaggio-Sandler model}

The implementation of DiMaggio-Sandler elastoplasticity model has been done using the plastic return-mapping in the rotated principal stresses and it is presented in Fig. 3 (left). The numerical integration scheme for DiMaggioSandler is verified by comparing the numerical results with two different ex- 
perimental test data. The experimental data are included a uniaxial compressive loading on the McCormic sand sample provided by (Sandler \& Rubin, 1979) and a triaxial loading on a salem limestone sample provided by (Fossum et al. 1995). The material parameters of these two tests are presented in Table 5 ,

Table 5. Parameters employed for verification of DiMaggio-Sandler plasticity model.

\begin{tabular}{|c|c|c|c|c|c|c|c|c|c|}
\hline Test data & $E$ & $\nu$ & $A$ & $B$ & $C$ & $D$ & $W$ & $X_{\circ}$ & $R$ \\
\hline Sandler 1979 & 100.0 & 0.25 & 0.25 & 0.67 & 0.18 & 0.67 & 0.066 & 0.0 & 2.5 \\
\hline Unit [unit] & $\mathrm{ksi}$ & & $\mathrm{ksi}$ & $\mathrm{ksi}^{-1}$ & $\mathrm{ksi}$ & $\mathrm{ksi}^{-1}$ & & $\mathrm{ksi}$ & \\
\hline Fossum 1995 & 23456.9 & 0.267 & 209.61 & $1.787 \times 10^{-3}$ & 198.49 & $3.909 \times 10^{-4}$ & 0.189 & -442.56 & 5.63 \\
\hline Unit [unit] & $\mathrm{MPa}$ & & $\mathrm{MPa}$ & $\mathrm{MPa}^{-1}$ & $\mathrm{MPa}$ & $\mathrm{MPa}^{-1}$ & & $\mathrm{MPa}$ & \\
\hline
\end{tabular}

Fig. 3 presents a comparison between the DiMaggio-Sandler implementation and the experimental results from articles (Sandler \& Rubin, 1979) and (Fossum et al., 1995) displaying the verification of the implementation.
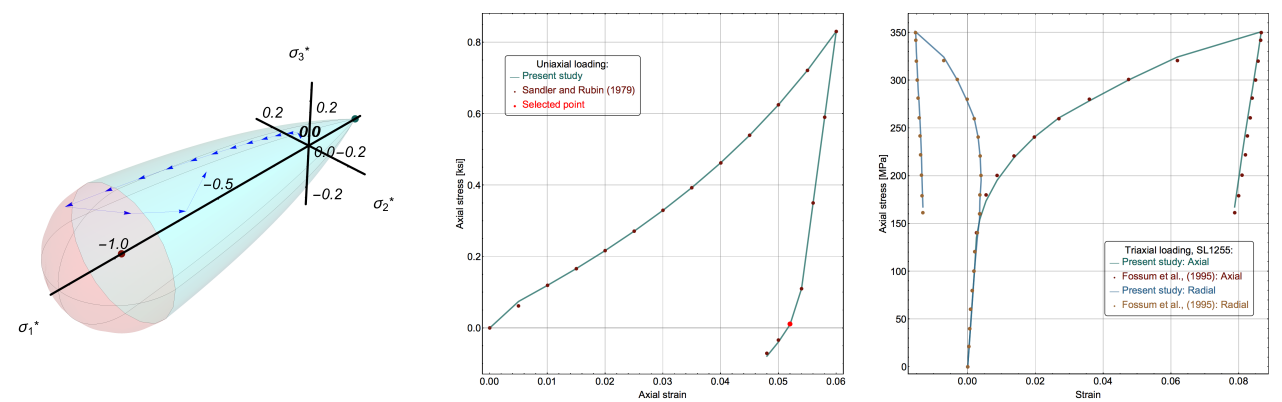

Figure 3. (left) DiMaggio-Sandler plasticity yield criterion in which failure function part is with a green color and cap function is with a red color, (middle) a comparison between numerical model of DiMaggio-Sandler with the experimental data reported by (Sandler \& Rubin 1979); the arrow with a blue color in the left shows the evolution of elastoplastic model which is represented here by a point with a red color, and (right) a comparison between numerical model of DiMaggio-Sandler with the experimental data provided by (Fossum et al., 1995) for the specimen SL1255. 


\subsection{Vertical wellbore for linear case}

For a vertical wellbore drilled in an isotropic elastic rock, analytical solutions for displacement and pore pressure are given by Coussy (2004), as follows:

For the pressure expression:

$$
p(r)=p_{w b}+\frac{p^{\circ}-p_{w b}}{\ln \left(\frac{r_{e}}{r_{w}}\right)} \ln \left(\frac{r}{r_{w}}\right)
$$

For the displacement expression:

$$
\mathbf{u}(r)=\frac{\sigma_{w b}+\sigma^{\circ}}{2 \mu} \frac{r_{w}^{2}}{r}
$$

The two-dimensional numerical mesh is performed by quadratic polynomial order for displacement and linear polynomial order for flux and pore pressure. The domain and boundary conditions for a vertical wellbore drilled is displayed in Fig. 4 (left). The material parameters are presented in Table 6. Fig. 5 shows the comparison of distributions of displacements, pressure, and flux. A good approximation is obtained using quadratic-linear elements. 
Table 6. Parameters employed for a vertical wellbore drilled.

\begin{tabular}{|c|c|c|}
\hline Parameter & Variable [unit] & Value \\
\hline \hline Young's modulus & $E \mathrm{MPa}$ & 1000.0 \\
\hline Poisson's ratio & $\nu$ & 0.2 \\
\hline Biot coefficient & $\alpha$ & 0 \\
\hline Fluid compressibility & $c_{f} \mathrm{MPa}^{-1}$ & 0 \\
\hline Fluid dynamic viscosity & $\eta \mathrm{Pa} \mathrm{s}^{-3}$ & $1 \times 10^{-3}$ \\
\hline Initial porosity & $\phi^{\circ}$ & 0.1 \\
\hline Initial Abs. permeability & $\kappa^{\circ} \mathrm{m}^{2}$ & $1 \times 10^{-13}$ \\
\hline Initial hydrostatic total stress & $\sigma^{\circ} \mathrm{MPa}$ & -50 \\
\hline Initial pressure excess & $p^{\circ} \mathrm{MPa}$ & 30 \\
\hline Mud pressure & $p_{w b} \mathrm{MPa}$ & 20 \\
\hline Internal BC normal stress & $\sigma_{w b}$ & -20 \\
\hline Tolerance for stop criterion & $\varepsilon_{u}=\varepsilon_{p}$ & $1 \times 10^{-7}$ \\
\hline
\end{tabular}
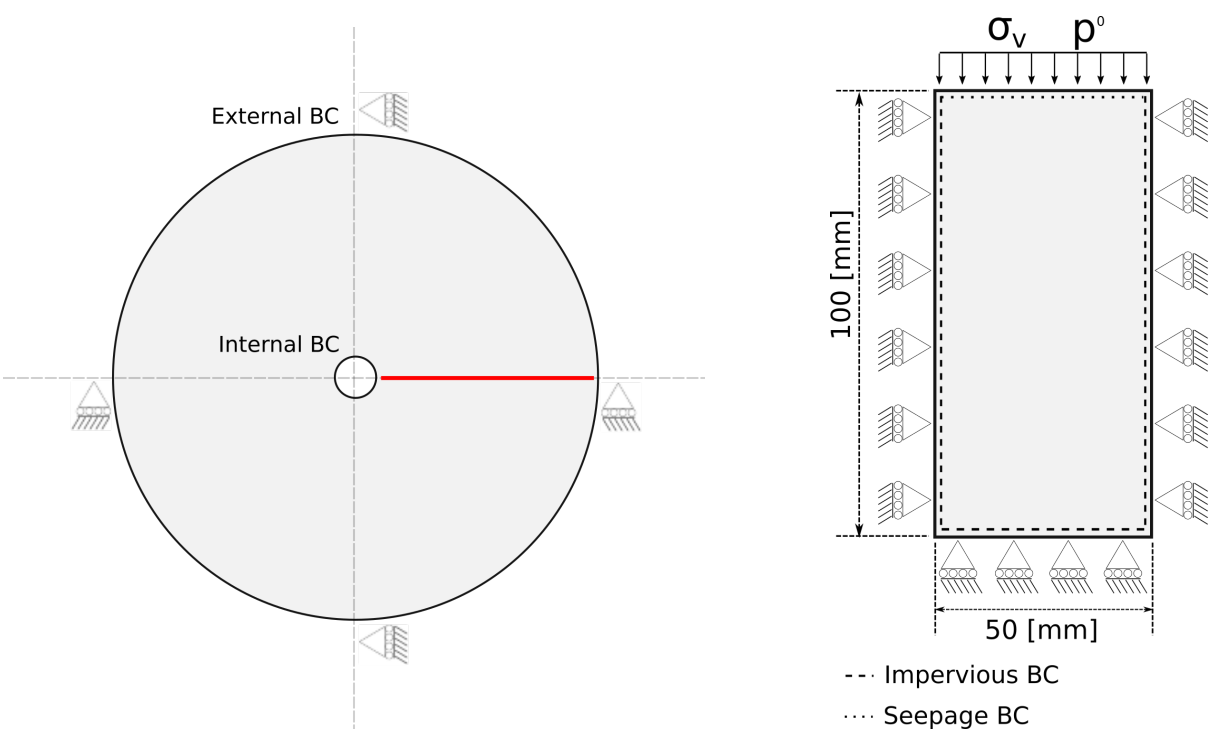

Figure 4. Domain and boundary conditions for: (left) vertical wellbore, and (right) uniaxial compression test. 

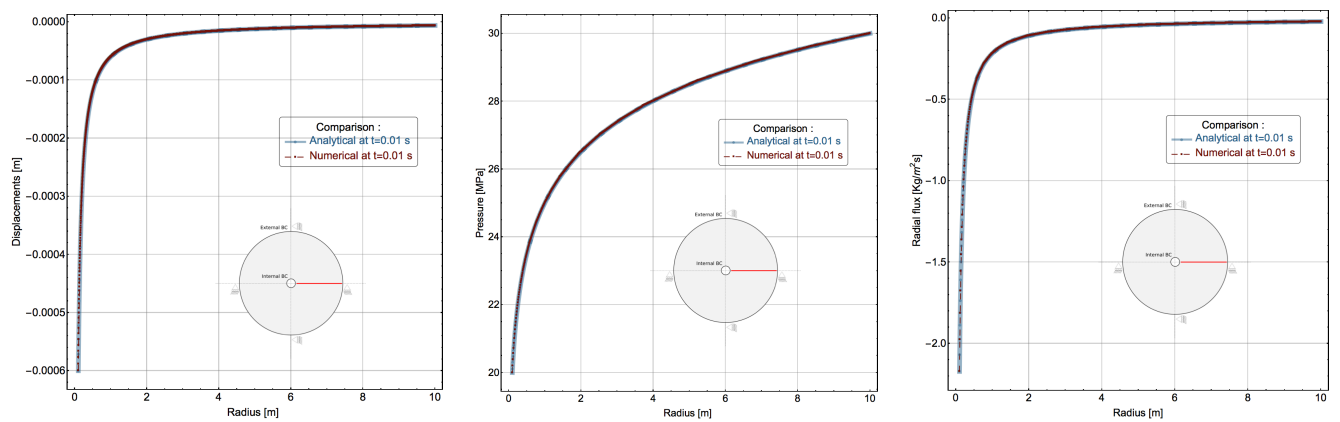

Figure 5. (left) Plot of displacement, (middle) pressure, and (right) flux.

\subsection{Vertical wellbore for nonlinear case}

In this study, we develop a reference solution for a vertical wellbore (boundary is shown in Fig. 4 (left) by reducing an axisymmetric boundary value problem (BVP) to an initial value problem (IVP) using Runge-Kutta solver. To construct a Runge-Kutta approximation, it is hypothesized that the coordinate is cylindrical $(r, \theta, z)$, the approximation is axisymmetric, and the condition is steady state. The Runge-Kutta is defined as:

$$
\frac{d \mathbf{y}}{d \mathbf{x}}=\mathbf{f}(\mathbf{y})
$$

The expression (38) is rewritten for coupled reservoir geomechanical modeling in terms of stress $\sigma_{r r}$ and pressure $p$, as follows: 


$$
\frac{d \mathbf{y}}{d \mathbf{x}}=\left\{\begin{array}{c}
\frac{d u_{r}}{d r} \\
\frac{d \sigma_{r r}}{d r} \\
\frac{d p}{d r} \\
\frac{d q_{r}}{d r}
\end{array}\right\} \text { and } \mathbf{f}(\mathbf{y})=\left\{\begin{array}{c}
\frac{r \sigma_{r r}-\lambda u_{r}}{r(\lambda+2 \mu)} \\
\frac{-\sigma_{r r}+\left(\frac{2 \mu u_{r}}{r}+\lambda\left(\frac{u_{r}}{r}+\frac{r \sigma_{r r}-\lambda u_{r}}{r(\lambda+2 \mu)}\right)\right)}{r}-\alpha \frac{\eta}{k} q_{r} \\
-\frac{\eta}{\kappa} q_{r} \\
-\frac{q_{r}}{r}
\end{array}\right\}
$$

The approximation above can be solved as an elastoplastic problem. The initial value problem $\mathbf{y}^{\circ}$ is evaluated at the reservoir radius $r_{e}$. The detail of the reference solution by using Runge-Kutta solver can be found in (Duran et al., 2019).

In this section, the iterative coupled reservoir geomechanical modeling for analyzing strain-dependent permeability is verified using a reference solution of axisymmetric Runge-Kutta $(R K)$. The geomechanics is presented by DiMaggio-Sandler elastoplastic model and the reservoir permeability is described using the permeability evolution models given in Table 4 The parameters employed to perform the simulations are presented in Table 7. 
Table 7. Parameters employed for axisymmetric Runge-Kutta and vertical wellbore.

\begin{tabular}{|c|c|c|}
\hline Parameter & Variable [unit] & Value \\
\hline Young's modulus & $E \mathrm{MPa}$ & 8000.0 \\
\hline Poisson's ratio & $\nu$ & 0.2 \\
\hline Biot's coefficient & $\alpha$ & 1 \\
\hline Fluid compressibility & $c_{f} \mathrm{MPa}^{-1}$ & 0 \\
\hline Fluid dynamic viscosity & $\eta \mathrm{Pas}$ & $1 \times 10^{-3}$ \\
\hline Initial porosity & $\phi^{\circ}$ & 0.12 \\
\hline Initial Abs. permeability & $\kappa^{\circ} \mathrm{m}^{2}$ & $4 \times 10^{-13}$ \\
\hline Permeability coefficient & $\bar{Z}$ & 10 \\
\hline$A$ & $\mathrm{MPa}$ & 40.5 \\
\hline$B$ & $\mathrm{MPa}^{-1}$ & 0.00028 \\
\hline$C$ & $\mathrm{MPa}$ & 18.0 \\
\hline$D$ & $\mathrm{MPa}^{-1}$ & 0.00001 \\
\hline$R$ & & 2.0 \\
\hline$W$ & & 0.00001 \\
\hline$X_{\circ}$ & $\mathrm{MPa}$ & -40.0 \\
\hline Initial hydrostatic total stress & $\sigma^{\circ} \mathrm{MPa}$ & -40.0 \\
\hline Initial pressure excess & $p^{\circ} \mathrm{MPa}$ & 30.0 \\
\hline Wellbore pressure & $p_{w} \mathrm{MPa}$ & 20.0 \\
\hline Internal BC normal stress & $\sigma_{w}$ & -20.0 \\
\hline Final time & $t_{\text {end }} \mathrm{s}$ & 100000000 \\
\hline
\end{tabular}

All the subfigures in the Figures 6, 7, 8, and 9 present a comparison for the sequential approximation with the Runge-Kutta approximation, showing verification of the models. A good approximation is obtained using a quadratic polynomial order for displacement and linear polynomial order for flux and pore pressure. The Fig. 6 (left) presents the variation of pore pressure, and (right) the variation of radial effective stress using a Costa permeability model with the coefficient $\varrho=1$ and $\mathcal{Z}=10$. 

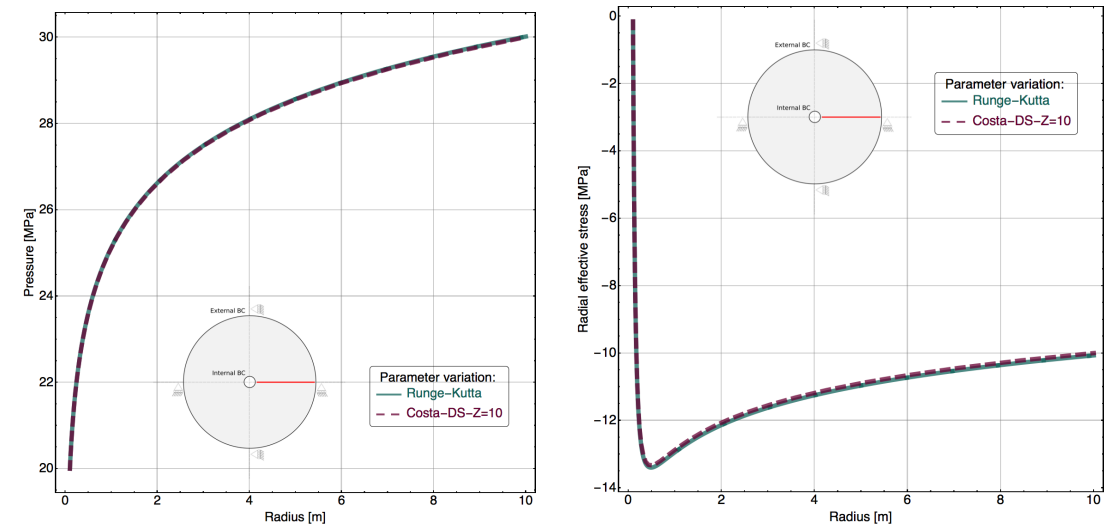

Figure 6. Nonlinear 2D case: steady state approximation for coupled DiMaggio-Sandler and Costa permeability model. (left) pressure, and (right) effective stress.

The Fig. 7 (left) presents the variation of pore pressure, and (right) the variation of radial effective stress using Petunin permeability model with the coefficient $\mathcal{Z}=10$.
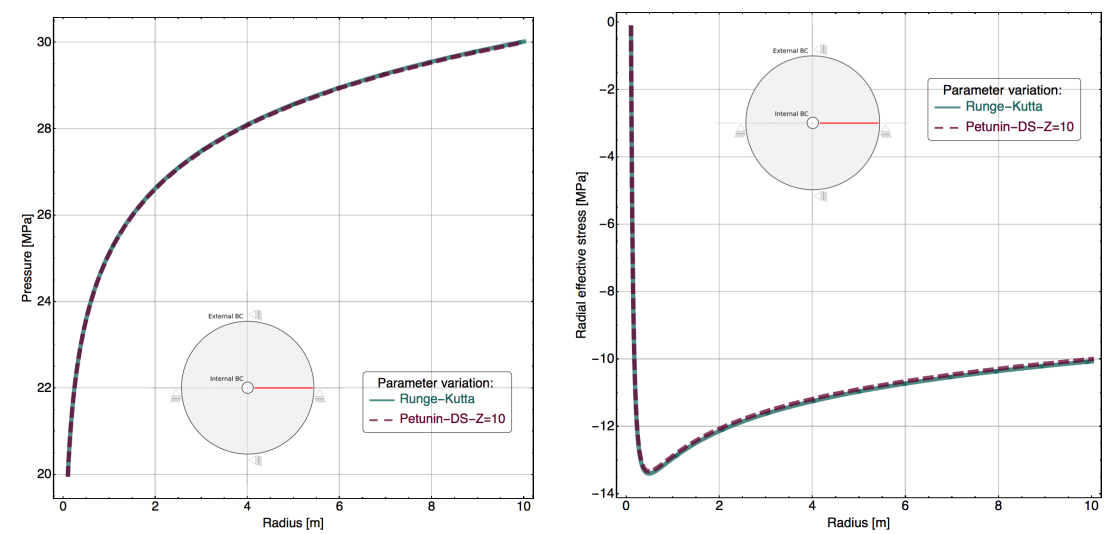

Figure 7. Nonlinear $2 D$ case: steady state approximation for coupled DiMaggio-Sandler and Petunin permeability model with the coefficient $\mathcal{Z}=10$. (left) pressure, and (right) effective stress.

The Fig. 8 (left) presents the variation of pore pressure, and (right) the variation of radial effective stress using the Nelson permeability model with 
the coefficient $\varrho=0$ and $\mathcal{Z}=10$.
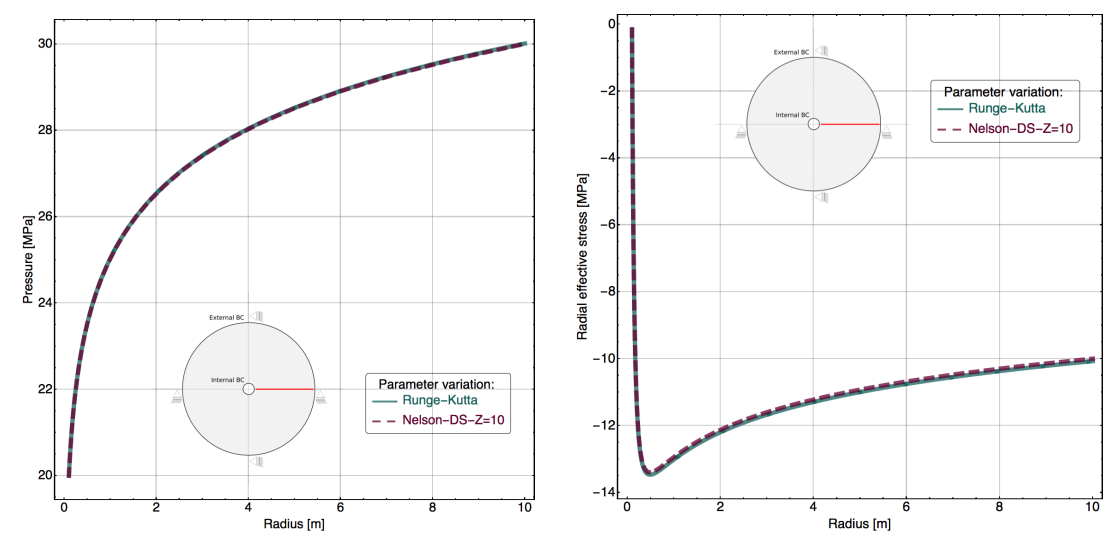

Figure 8. Nonlinear 2D case: steady state approximation for coupled DiMaggio-Sandler and Nelson permeability model with the coefficient $\varrho=0$ and $\mathcal{Z}=10$. (left) pressure, and (right) effective stress.

The Fig. 9 (left) presents the variation of pore pressure, and (right) the variation of radial effective stress using a Davies permeability model with the coefficient $\mathcal{Z}=10$.
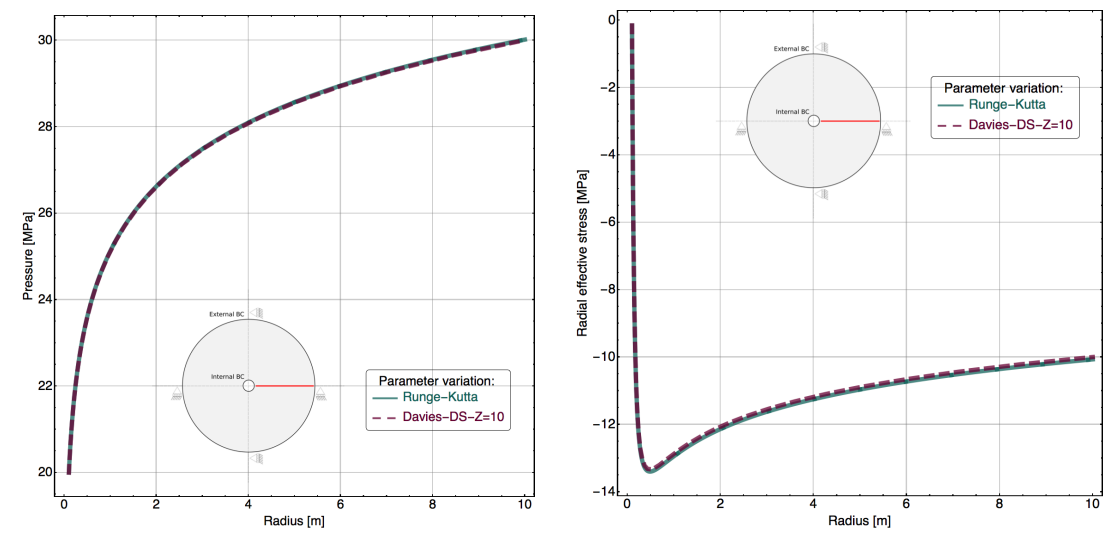

Figure 9. Nonlinear $2 D$ case: steady state approximation for coupled DiMaggio-Sandler and Davies permeability model with the coefficient $\mathcal{Z}=10$. (left) pressure, and (right) effective stress. 


\section{Results and Discussions}

The strain-dependent permeability $(S D P)$ and its impact on production are analyzed using coupled reservoir and geomechanical modeling. The strain is represented using DiMaggio-Sandler elastoplastic model and permeability is defined using the nonlinear permeability models provided in Table 4 . The following numerical tests are implemented, such as: (1) homogeneous stress state of uniaxial compression test, (2) two-dimensional model of vertical reservoir production, (3) three-dimensional model of vertical reservoir.

\subsection{Uniaxial compression test}

The strain-dependent permeability is analyzed numerically by implementing a uniaxial compression test. The numerical model is done using a homogeneous stress states. The material properties for the uniaxial test are given in Table 8. Fig. 4 (right) is representative of the equivalent loading condition. The uniaxial test is modeled in a stress-rate control where the vertical stress on the top of the specimen is increased from (-1 MPa to $-20 \mathrm{MPa})$. The bottom and lateral displacement are restricted to zero displacement. Hydraulic boundary conditions are set as follows: the initial pore pressure boundary and a constant pressure $p=1 \mathrm{MPa}$ are applied on the top of specimen and the impermeable boundaries on the bottom and lateral boundaries of specimen. The evolution of loading applied on the sample to reach the final stresses is done in 20 states. 
Table 8. Parameters employed for uniaxial test to analyze strain-dependent permeability.

\begin{tabular}{|c|c|c|}
\hline Parameter & Variable [unit] & Value \\
\hline \hline Young's modulus & $E \mathrm{MPa}$ & 3800.0 \\
\hline Poisson's ratio & $\nu$ & 0.2 \\
\hline Biot's coefficient & $\alpha$ & 1 \\
\hline Fluid compressibility & $c_{f} \mathrm{MPa}^{-1}$ & 0 \\
\hline Fluid dynamic viscosity & $\eta \mathrm{Pa}^{\circ}$ & $1 \times 10^{-3}$ \\
\hline Initial porosity & $\phi^{\circ}$ & 0.12 \\
\hline Initial Abs. permeability & $\kappa^{\circ} \mathrm{m}^{2}$ & $1 \times 10^{-13}$ \\
\hline Petunin coefficient & $\mathcal{Z}$ & 20 \\
\hline$A$ & $\mathrm{MPa}$ & 40.0 \\
\hline$B$ & $\mathrm{MPa}$ & 0.02 \\
\hline$C$ & $\mathrm{MPa}$ & 35.0 \\
\hline$D$ & $\mathrm{MPa}$ & 0.006 \\
\hline$R$ & & 3.0 \\
\hline$W$ & & 0.025 \\
\hline$X_{\circ}$ & $\mathrm{MPa}$ & -45.0 \\
\hline Initial vertical total stress & $\sigma_{v}^{\circ} \mathrm{MPa}$ & -1.0 \\
\hline Initial pressure excess & $p^{\circ} \mathrm{MPa}$ & 1.0 \\
\hline Vertical total stress & $\sigma_{v} \mathrm{MPa}$ & -1.0 to -20.0 \\
\hline
\end{tabular}

To represent the strain-dependent permeability using coupled DiMaggioSandler plasticity and Petunin permeability model, the results of a material point subject to evolving stresses is studied. The results of the uniaxial compression test to analyze strain-dependent permeability is shown in Fig. [10.

The results in Fig. 10 illustrate that the strain-dependent permeability can be described using coupled reservoir geomechanical modeling. The results demonstrate that porosity and permeability decrease with increasing the strain. 

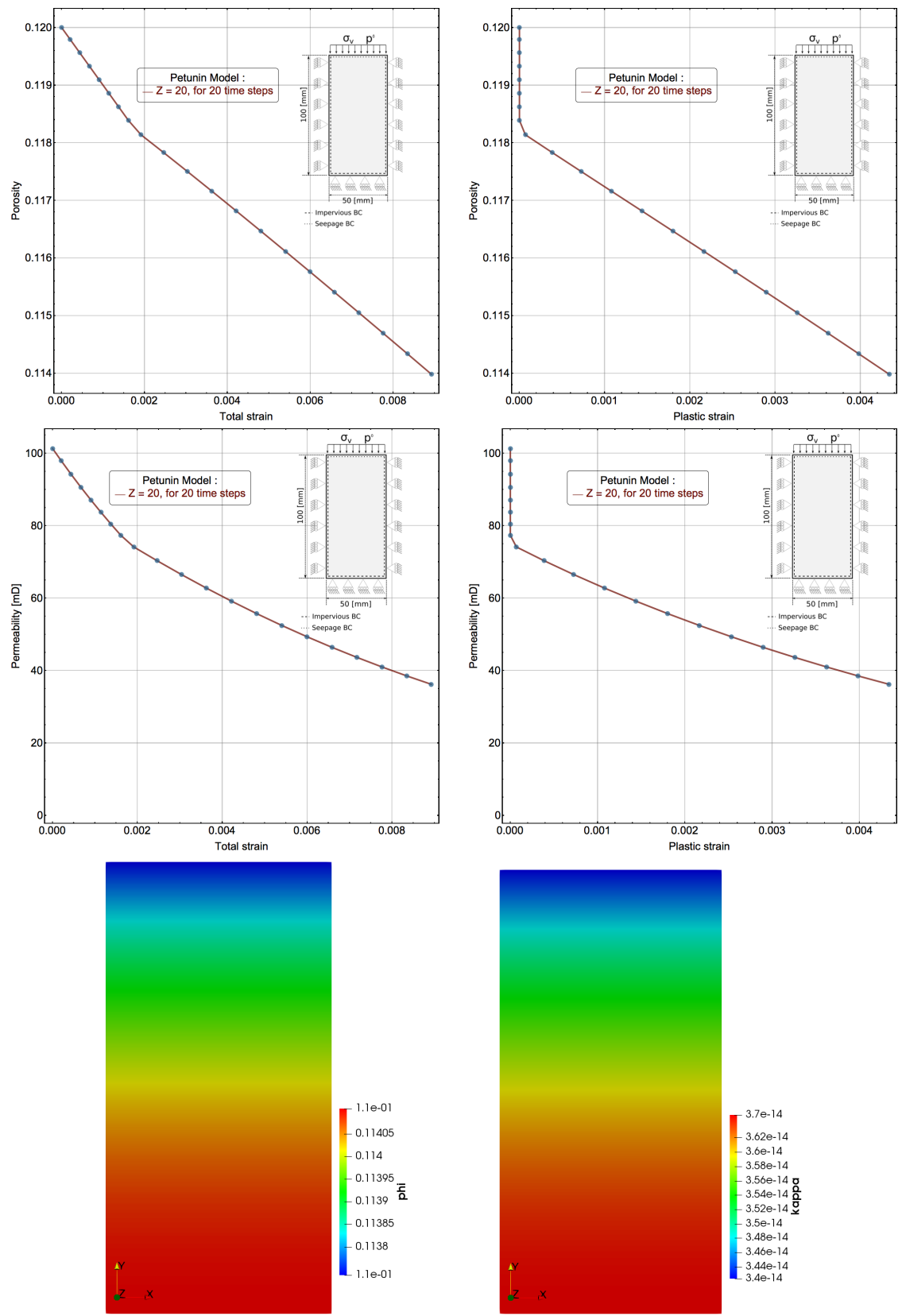

Figure 10. 2D model of uniaxial test to see strain-dependent permeability using a Petunin model with $\mathcal{Z}=20$ : (top-left) relation between porosity and total strain, (top-right) relation between porosity and plastic strain, (middle-left) relation between permeability and total strain, (middle-right) relation between permeability and plastic strain, (bottomleft) distribution of porosity, and (bottom-right) distribution of permeability at $t=1.0 \mathrm{~s}$. 


\subsection{Two-dimensional model of vertical reservoir production}

Generally, the use of open-hole completions in the design of production wells is a specially appealing choice for oil companies because its profitable compared to the standard cased hole (Capasso et al. 2008). To analyze the impact of strain-dependent permeability on reservoir productivity, a $2 D \mathrm{nu}-$ merical model is implemented. The numerical mesh is composed of quadratic polynomial order elements for displacement and linear Raviart Thomas flux/pore pressure pairs for the fluid approximation. The model of cylindrical reservoir includes a vertical well with the radius $r_{w}=0.1 \mathrm{~m}$ in open hole completion and the outer boundary of reservoir, extending to $r_{o}=10.0 \mathrm{~m}$. The simulation is conducted as follows. First, the initial state of the reservoir is calculated based on a pore pressure of $50.0[\mathrm{MPa}]$ and an external stress of $60[\mathrm{MPa}]$ is imposed on both inner and outer boundaries of the reservoir. Next, the stress around wellbore is changed to a reservoir pressure of 50.0 [MPa] to simulate the open-hole completion. Finally, a series of decreasing fluid pressure with the same length of time for a total time span of 10 days is applied at the inner boundary of the wellbore, as given in Table 9 .

Table 9. A series of decreasing fluid pressure for a $2 D$ cylindrical reservoir.

\begin{tabular}{|c|c|c|c|c|c|c|c|c|c|c|}
\hline Time [d] & 1 & 2 & 3 & 4 & 5 & 6 & 7 & 8 & 9 & 10 \\
\hline Well pressure $\mathrm{MPa}$ & 50 & 47 & 44 & 41 & 38 & 35 & 32 & 29 & 26 & 23 \\
\hline
\end{tabular}

The numerical model is implemented using coupled DiMaggio-Sandler elastoplastic model and four types of permeability models, including Costa, Petunin, Nelson, and Davies. To evaluate the impact of strain-dependent 
permeability on the various reservoir rocks, two different quantities of coefficient $\mathcal{Z}$, namely 20,40 are used. The model parameters are given in Table 10.

Table 10. Parameters employed for strain-dependent permeability on a $2 D$ reservoir productivity.

\begin{tabular}{|c|c|c|}
\hline Parameter & Variable [unit] & Value \\
\hline \hline Young's modulus & $E \mathrm{MPa}$ & 8000.0 \\
\hline Poisson's ratio & $\nu$ & 0.2 \\
\hline Biot's coefficient & $\alpha$ & 1 \\
\hline Fluid compressibility & $c_{f} \mathrm{MPa}^{-1}$ & 0 \\
\hline Fluid dynamic viscosity & $\eta \mathrm{Pa} \mathrm{s}^{\circ}$ & $1 \times 10^{-3}$ \\
\hline Initial porosity & $\phi^{\circ}$ & 0.12 \\
\hline Initial Abs. permeability & $\kappa^{\circ} \mathrm{m}^{2}$ & $4 \times 10^{-13}$ \\
\hline Permeability coefficient & $\mathcal{Z}$ & 20 and 40 \\
\hline$A$ & $\mathrm{MPa}$ & 40.5 \\
\hline$B$ & $\mathrm{MPa}^{-1}$ & 0.00028 \\
\hline$C$ & $\mathrm{MPa}^{-1}$ & 18.0 \\
\hline$D$ & $\mathrm{MPa}$ & 0.00001 \\
\hline$R$ & & 2.0 \\
\hline$W$ & & 0.00001 \\
\hline$X_{\circ}$ & $\mathrm{MPa}$ & -40.0 \\
\hline Initial hydrostatic total stress & $\sigma^{\circ} \mathrm{MPa}$ & -60.0 \\
\hline Initial pressure excess & $p^{\circ} \mathrm{MPa}$ & 50.0 \\
\hline Time step size & $\Delta t \mathrm{~d}$ & 1.0 \\
\hline Final time & $t_{\text {end }} \mathrm{d}$ & 10.0 \\
\hline
\end{tabular}

\subsubsection{D model of vertical reservoir using Costa permeability model}

To analyze the field variable profiles due to drawdown in open hole completion, the $2 D$ numerical test of coupled reservoir geomechanical by considering Costa permeability in the cylindrical reservoir is implemented. The quantity of coefficient $\varrho$ is 1 and coefficient $\mathcal{Z}$ is 20 and 40 . The impact of strain-dependent permeability on reservoir productivity using a Costa model is shown in Fig. 11, in which the results belong to time $t=2,6,10[\mathrm{~d}]$. 
All the subfigures in the Fig. 11 present a comparison of the variables due to the various quantities of $\mathcal{Z}$. Near to the wellbore, it can be observed less increments of radial flux and more reduction of porosity and permeability because of the increase the $\mathcal{Z}$ value from 20 to 40 . In addition, the Fig. 11 at middle-right and bottom-left illustrate that the porosity and permeability are decreased by reducing the fluid pressure. The Fig. 11 at bottom-right shows the variation of radial flux near the wellbore. It can be seen that from only geomechanical effects the wellbore region deteriorates the productivity index associated with the case when is considered a constant permeability and no geomechanical effects. 

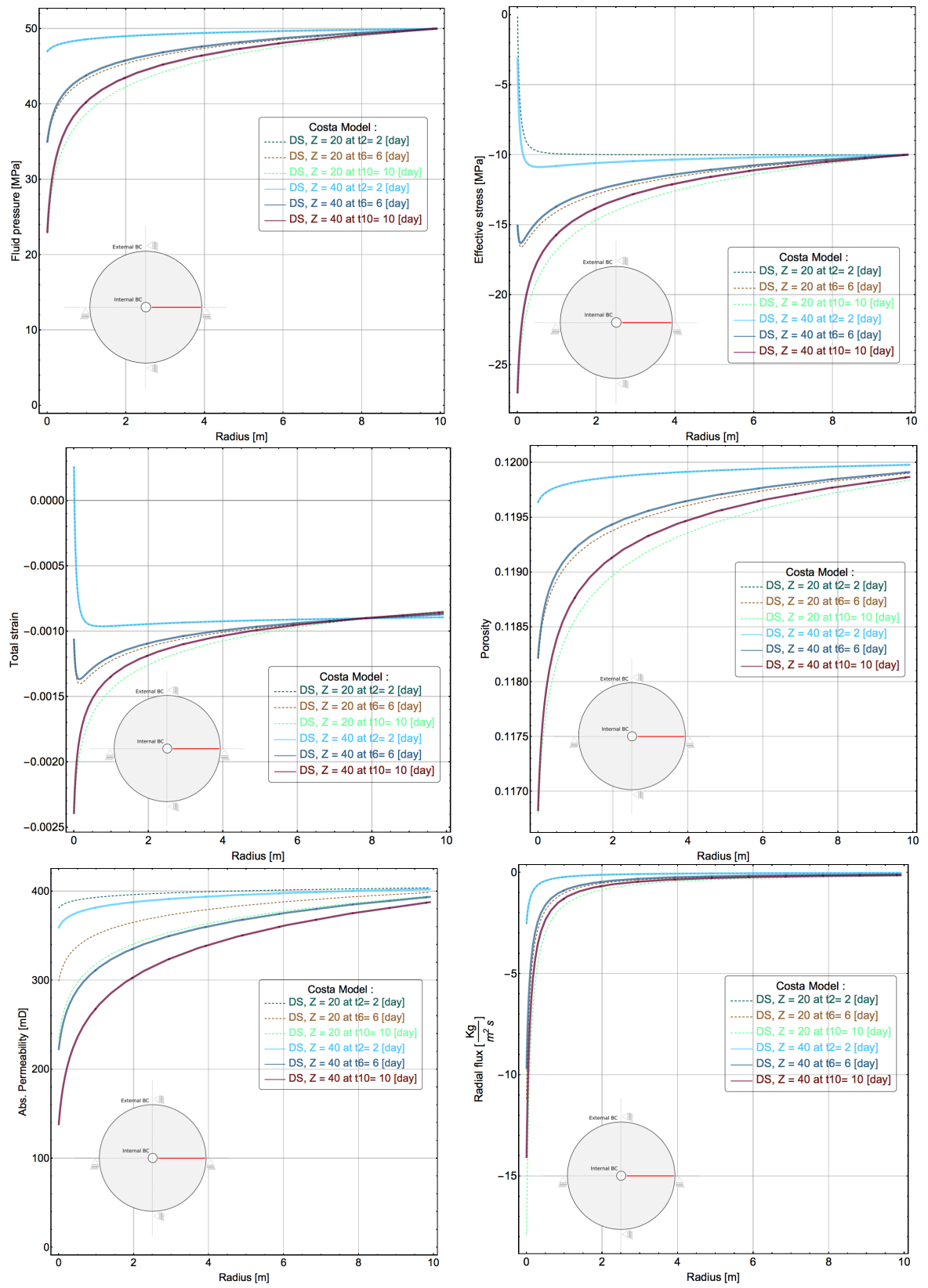

Figure 11. 2D model of the cylindrical reservoir to analyze the effect of strain-dependent permeability on productivity using the Costa model. (top-left) fluid pressure, (top-right) effective stress in $x$ direction, (middle-left) strain in $x$ direction, (middle-right) porosity, (bottom-left) absolute permeability, and (bottom-right) flux. 


\subsubsection{D model of vertical reservoir using Petunin permeability model}

Implement the same model for the last subsection with considering Petunin permeability model. The quantity of coefficient $\mathcal{Z}$ is 20 and 40 . The impact of strain-dependent permeability on reservoir productivity using a Petunin model is presented in Fig. 12, the results belong to time $t=2,6,10$ [d].

All the subfigures in the Fig. 12 display a comparison of the variables because of the various quantities of $\mathcal{Z}$. Near to the wellbore, it can be seen less increments of radial flux and more reduction of porosity and permeability due to the increase the $\mathcal{Z}$ value from 20 to 40 . In addition, the Fig. 12 at middle-right and bottom-left indicate that the porosity and permeability are decreased by reducing the fluid pressure. The Fig. 12 at bottom-right shows the variation of radial flux near the wellbore. It can be observed that from only geomechanical effects the wellbore region deteriorates the productivity index associated with the case when is considered a constant permeability and no geomechanical effects.

\subsubsection{D model of vertical reservoir using Nelson permeability model}

Implement the same model for the last subsection with considering Nelson permeability model. The quantity of coefficient $\varrho$ is 0 and coefficient $\mathcal{Z}$ is 20 and 40 . The impact of strain-dependent permeability on reservoir productivity using a Nelson model with $\mathcal{Z}=20$ and $\mathcal{Z}=40$ are shown in Fig. 13 .

Fig. 13 presents a comparison of the variables because of the various 
quantities of $\mathcal{Z}$. Near to wellbore, it can be observed less increments of radial flux and more reduction of porosity and permeability due to the increase the $\mathcal{Z}$ value from 20 to 40 . In addition, Fig. 13 at middle-right and bottom-left show that the porosity and permeability are decreased by reducing the fluid pressure. The Fig. 13 at bottom-right illustrates the change of radial flux near the wellbore. It can be seen that from only geomechanical effects the wellbore deteriorates the productivity index associated with the case when is considered a constant permeability and no geomechanical effects.

\subsubsection{D model of vertical reservoir using Davies permeability model}

Implement the same model for the last subsection with considering Davies permeability model. The quantity of coefficient $\mathcal{Z}$ is 20 and 40 . The effect of strain-dependent permeability on reservoir productivity using a Davies model with $\mathcal{Z}=20$ and $\mathcal{Z}=40$ are displayed in Fig. 14 . 

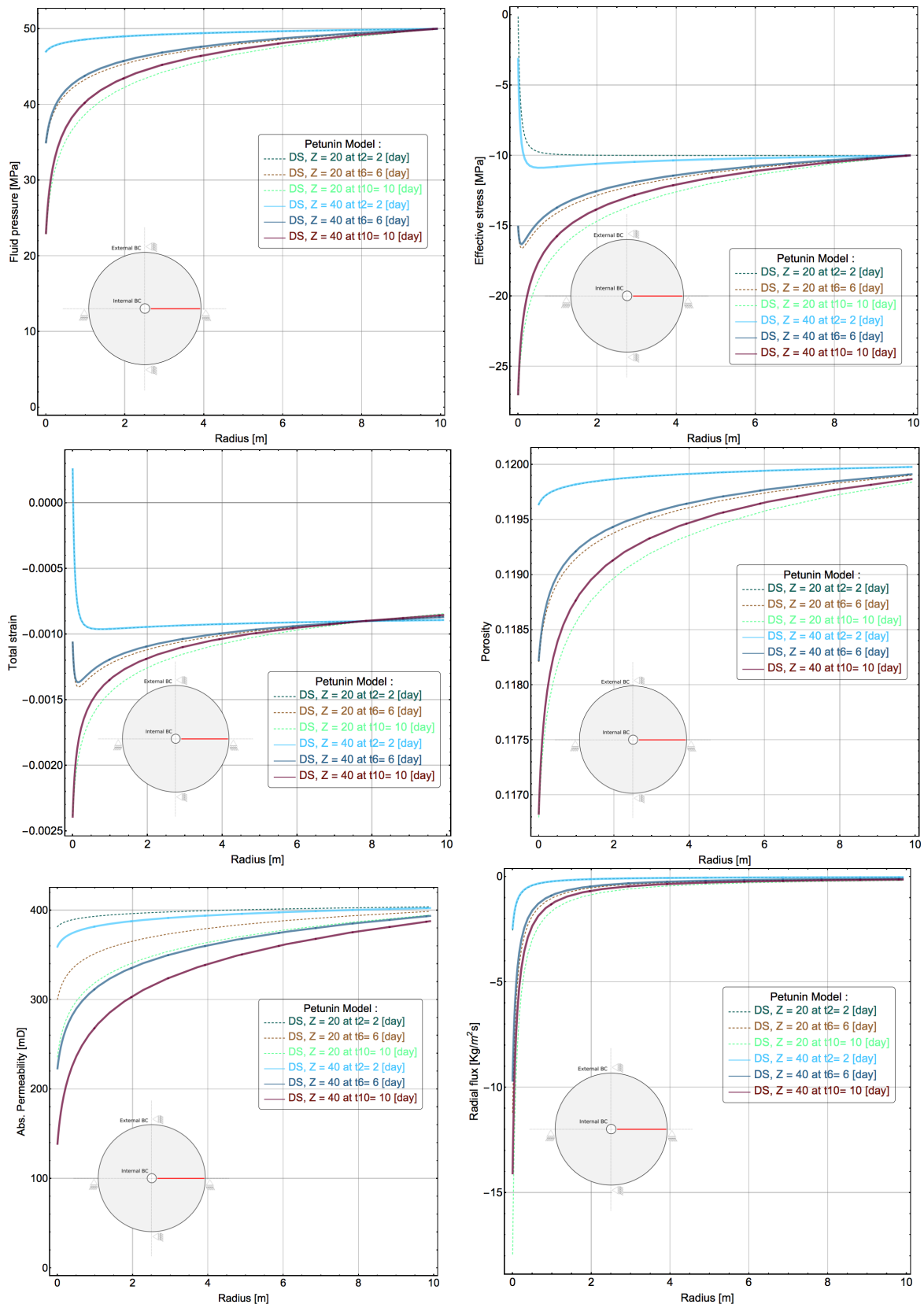

Figure 12. $2 D$ model of the cylindrical reservoir to analyze the effect of strain-dependent permeability on productivity using the Petunin model. (top-left) fluid pressure, (top-right) effective stress in $x$ direction, (middle-left) strain in $x$ direction, (middle-right) porosity, (bottom-left) absolute permeability, and (bottom-right) flux. 

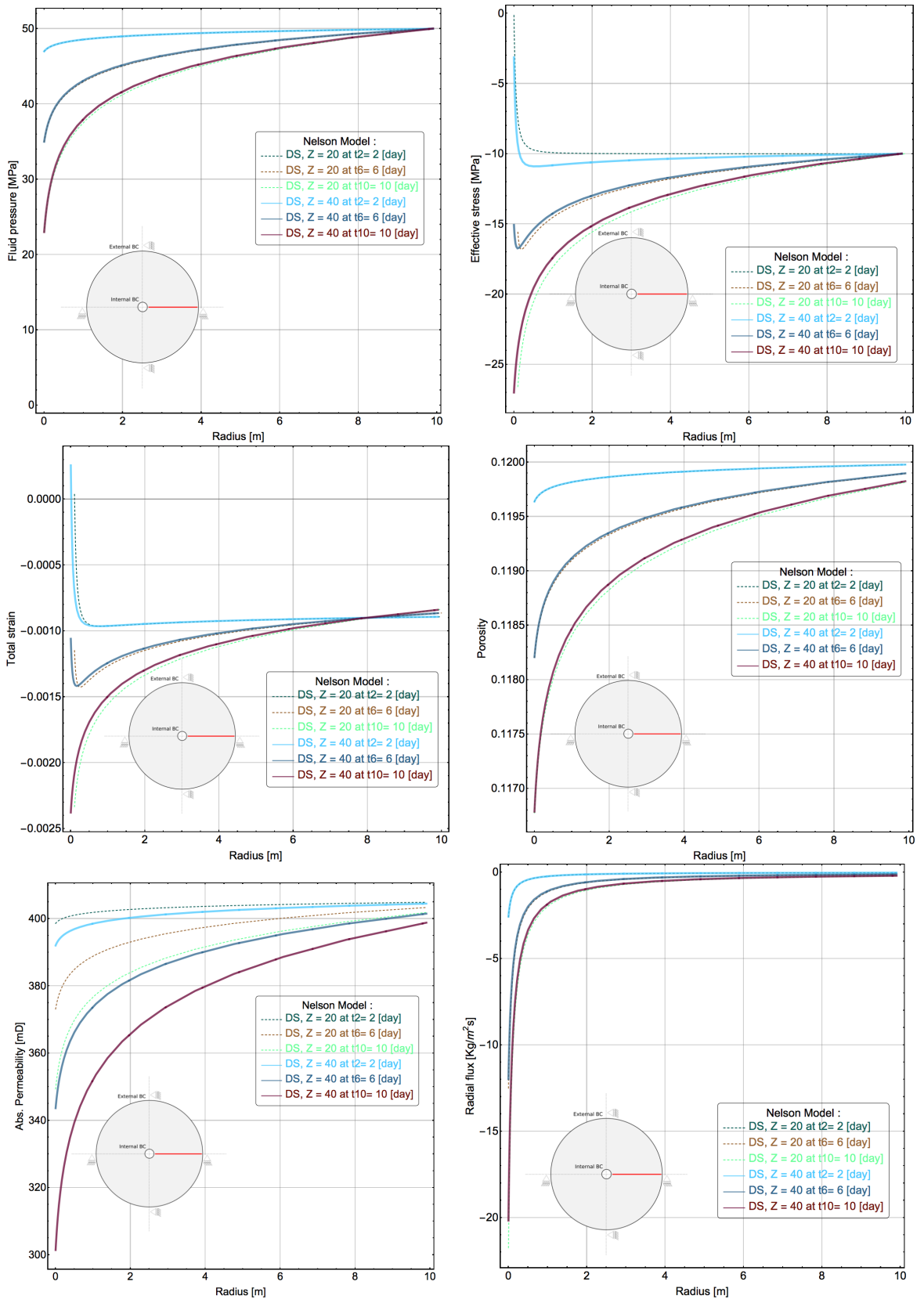

Figure 13. 2D model of the cylindrical reservoir to analyze the effect of strain-dependent permeability on productivity using the Nelson model. (top-left) fluid pressure, (top-right) effective stress in $x$ direction, (middle-left) strain in $x$ direction, (middle-right) porosity, (bottom-left) absolute permeability, and (bottom-right) flux. 

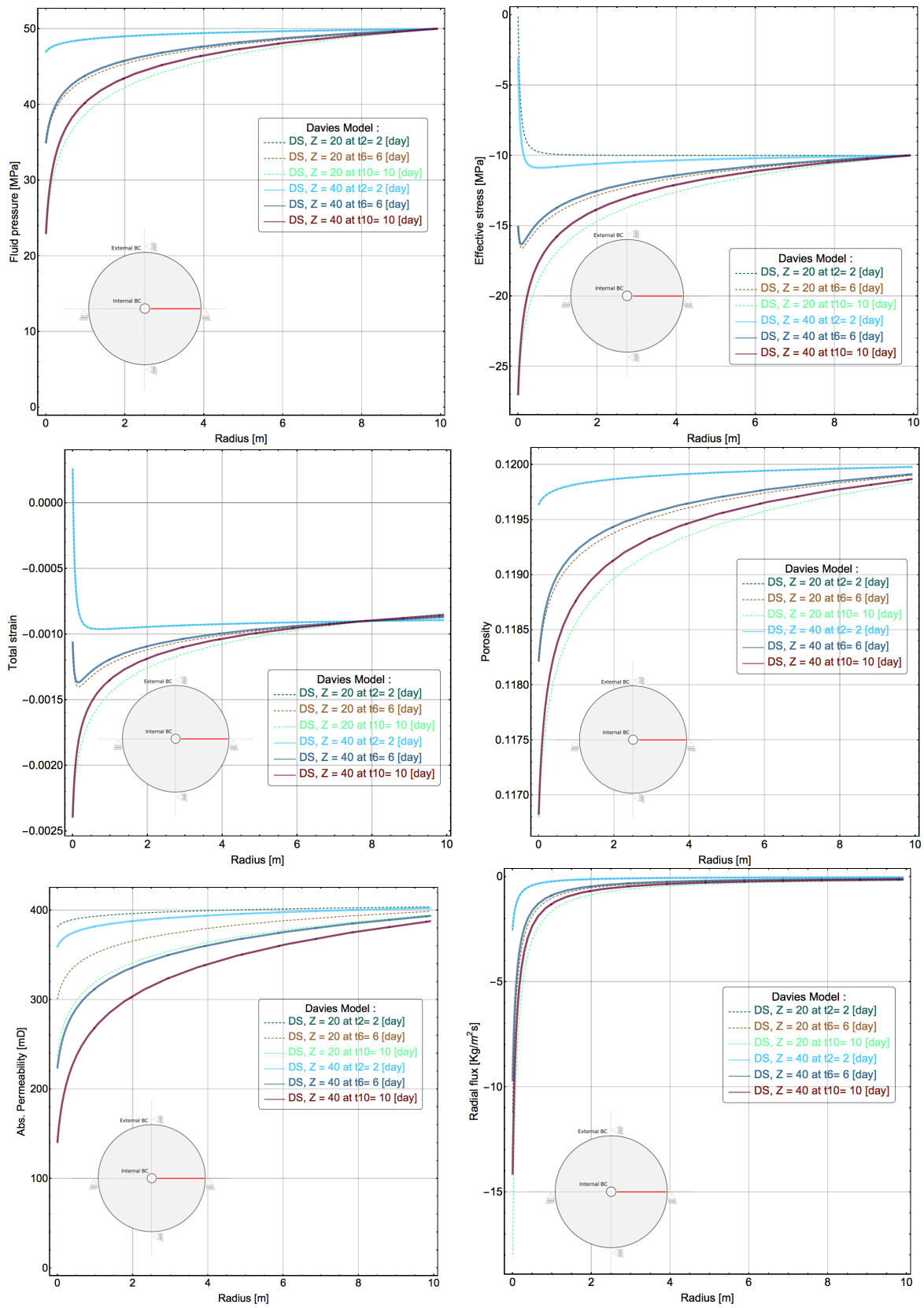

Figure 14. 2D model of the cylindrical reservoir to analyze the effect of strain-dependent permeability on productivity using the Davies model. (top-left) fluid pressure, (top-right) effective stress in $x$ direction, (middle-left) strain in $x$ direction, (middle-right) porosity, (bottom-left) absolute permeability, and (bottom-right) flux. 
All the subfigures in the Fig. 14 indicate a comparison of the variables because of the various quantities of $\mathcal{Z}$. Near to the wellbore, it can be observed less increments of radial flux and more reduction of porosity and permeability due to the increase the $\mathcal{Z}$ value from 20 to 40 . In addition, the Fig. 14 at middle-right and bottom-left illustrate that the porosity and permeability are decreased by reducing the fluid pressure. The Fig. 14 at bottom-right shows the variation of radial flux near the wellbore. It can be seen that from only geomechanical effects the wellbore region deteriorates the productivity index associated with the case when is considered a constant permeability and no geomechanical effects.

\subsection{Three-dimensional model of vertical reservoir}

The petroleum industry uses a large number of well production and injection to produce and enhance hydrocarbon recovery. Consequently, the purpose of this section is to describe the effect of strain-dependent permeability on the field variables when the wellbore in reservoir receives both the decrease and increase of fluid pressure.

The implementation of the $3 D$ numerical test is similar to last section with considering a vertical wellbore with the radius $r_{w}=0.1 \mathrm{~m}$ and extending the outer boundary of reservoir to $r_{o}=10.0 \mathrm{~m}$. The numerical mesh is composed of quadratic polynomial order elements for displacement and linear Raviart Thomas flux/pore pressure pairs for the fluid approximation. The model parameters are given in Table 11 . 
Table 11. Material parameters employed for strain-dependent permeability in a $3 D$ reservoir.

\begin{tabular}{|c|c|c|}
\hline Parameter & Value & Variable [unit] \\
\hline \hline Young's modulus & 5000.0 & $E \mathrm{MPa}$ \\
\hline Poisson's ratio & 0.2 & $\nu$ \\
\hline Biot's coefficient & 1 & $\alpha$ \\
\hline Fluid compressibility & 0 & $c_{f} \mathrm{MPa}^{-1}$ \\
\hline Fluid dynamic viscosity & $1 \times 10^{-3}$ & $\eta \mathrm{Pa}^{\mathrm{s}}$ \\
\hline Initial porosity & 0.12 & $\phi^{\circ}$ \\
\hline Initial Abs. permeability & $1 \times 10^{-13}$ & $\kappa^{\circ} \mathrm{m}^{2}$ \\
\hline Permeability coefficient & 10.0 and 25.0 & $\mathcal{Z}$ \\
\hline$A$ & 50.0 & $\mathrm{MPa}^{-1}$ \\
\hline$B$ & 0.027 & $\mathrm{MPa}^{-1}$ \\
\hline$C$ & 40.0 & $\mathrm{MPa}$ \\
\hline$D$ & 0.0005 & $\mathrm{MPa}$ \\
\hline$W$ & 0.0012 & \\
\hline$R$ & 3.0 & $\mathrm{MPa}$ \\
\hline$X_{\circ}$ & -74.0 &
\end{tabular}

The simulation is conducted as follows. First, the initial state of reservoir is computed based on a pore pressure of $50.0[\mathrm{MPa}]$ and an external stress of $60[\mathrm{MPa}]$ is imposed on both inner and outer boundaries of the reservoir. Then, the stress around wellbore is changed to a reservoir pressure of 50.0 $[\mathrm{MPa}]$ to simulate the open-hole completion. Afterwards, a series of decreasing fluid pressure with the same length of time for a total time span of 10 days is applied at the inner boundary of the wellbore. Finally, a series of increasing pressure with the same length of time for a total time span of 10 days is applied at the inner boundary of the wellbore, as given in Table 12 . 
Table 12. A series of decreasing and increasing fluid pressure for a vertical well.

\begin{tabular}{|c|c|c|c|c|c|c|c|c|c|c|}
\hline Time [d] & 1 & 2 & 3 & 4 & 5 & 6 & 7 & 8 & 9 & 10 \\
\hline Decrease fluid pressure MPa & 50 & 47 & 44 & 41 & 38 & 35 & 32 & 29 & 26 & 23 \\
\hline \hline Time [d] & 11 & 12 & 13 & 14 & 15 & 16 & 17 & 18 & 19 & 20 \\
\hline Increase fluid pressure MPa & 23 & 26 & 29 & 32 & 35 & 38 & 41 & 44 & 47 & 50 \\
\hline
\end{tabular}

The Fig. 15 (top), presents the variation of fluid pressure versus radial distance from wellbore, in which the fluid pressure decreases from 50 [MPa] to $23[\mathrm{MPa}]$ for a total time of $10[\mathrm{~d}]$. Then, the fluid pressure increases from $23[\mathrm{MPa}]$ to $50[\mathrm{MPa}]$ for a total time of $10[\mathrm{~d}]$. The variation of fluid pressure leads to increase effective stress and total strain, as shown in Fig. 15 (middle) and (bottom). The Fig. 15 at top-right, middle-right and bottomright illustrate that although the pressure drop is reached zero, the quantity of effective stress and total strain are not equal to their initial value. All the subfigures in the Fig. 15 indicate a comparison of the variables due to the various quantities of $\mathcal{Z}$, namely 10.0 and 25.0 .

The Fig. 16 at top and middle positions show that the variation of porosity and permeability because of the change of fluid pressure. The Fig. 16 at bottom position presents the variation of radial flux near the wellbore. The results of Fig. 16 at top-right and middle-right positions provide an important reason to consider strain-dependent permeability in reservoir simulation, where the lost some percent of porosity and permeability are due to the increment of effective stress and deformation (see in Fig. 15 (middleright) and (bottom-right)). The Fig. 16 can be observed that from only geomechanical effects the wellbore region deteriorates the productivity index 
associated with the case when is considered a constant permeability and no geomechanical effects. In addition, the distribution of variables near to the wellbore are presented in Fig. 17. 

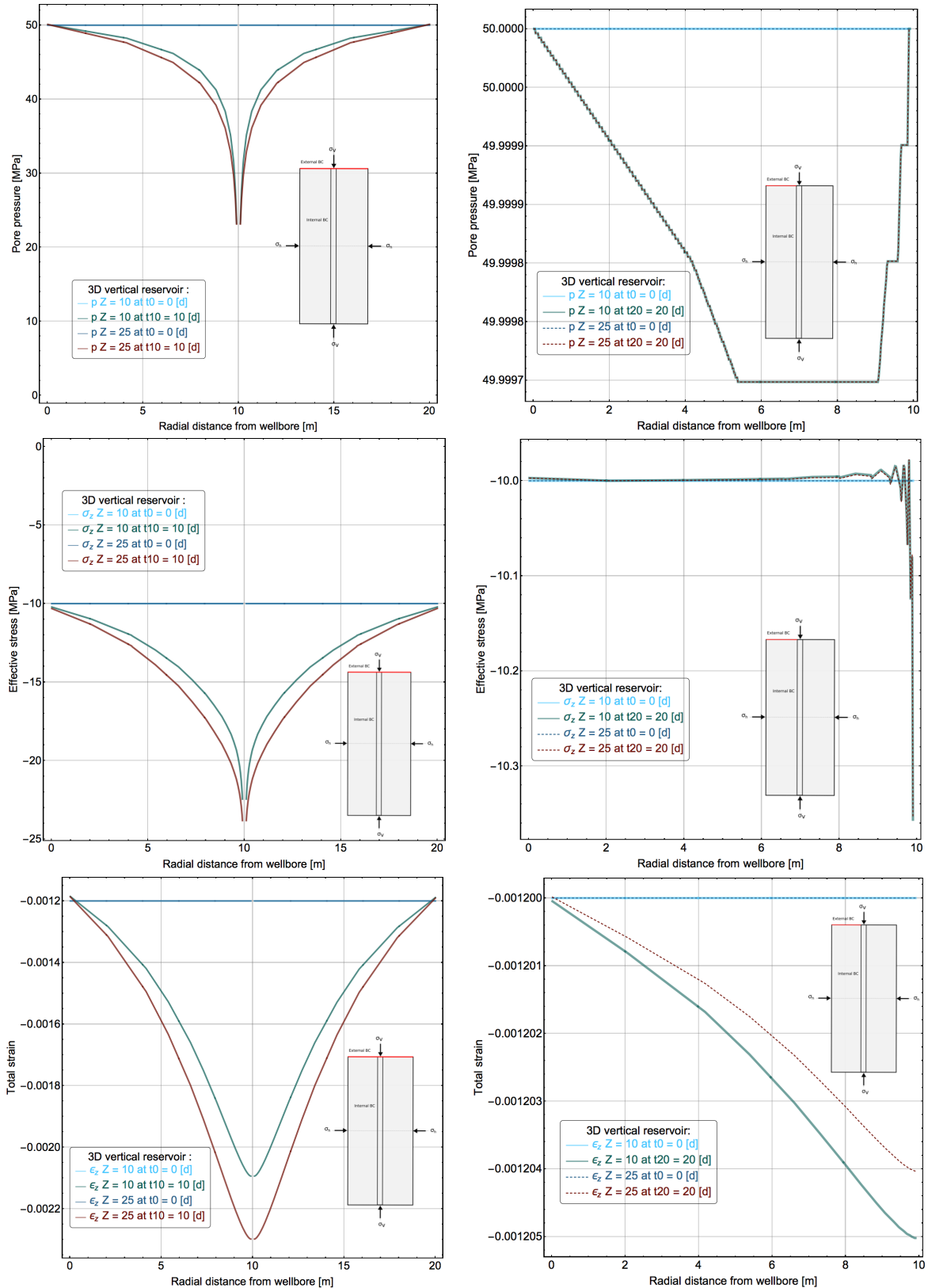

Figure 15. $3 D$ model of the vertical reservoir to analyze the effect of strain-dependent permeability on productivity using the Petunin model. (top-left) variation of fluid pressure after 10 days production, (top-right) variation of fluid pressure after 20 days, (middle-left) variation of effective stress in $z$ direction after 10 days production, (middle-right) variation of effective stress in $z$ direction after 20 days, (bottom-left) variation of strain in $z$ direction after 10 days production, (bottom-right) variation of strain in $z$ direction after 20 days. 

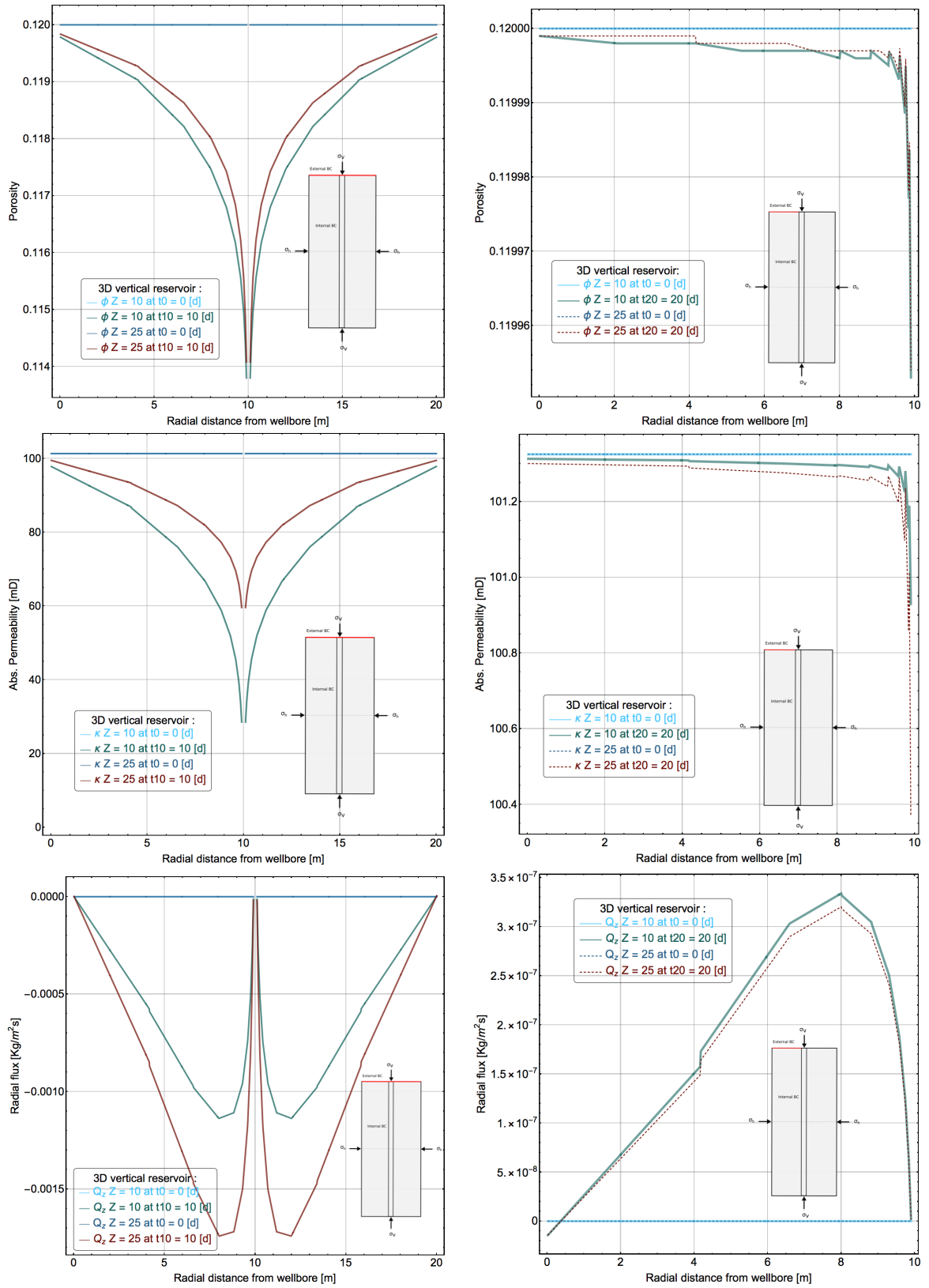

Figure 16. $3 D$ model of the vertical reservoir to analyze the effect of strain-dependent permeability on productivity using the Petunin model. (top-left) variation of porosity after 10 days production, (top-right) variation of porosity after 20 days, (middle-left) variation of permeability after 10 days production, (middle-right) variation of permeability after 20 days, (bottom-left) variation of flux in $z$ direction after 10 days production, (bottom-right) variation of flux in $z$ direction after 20 days. 

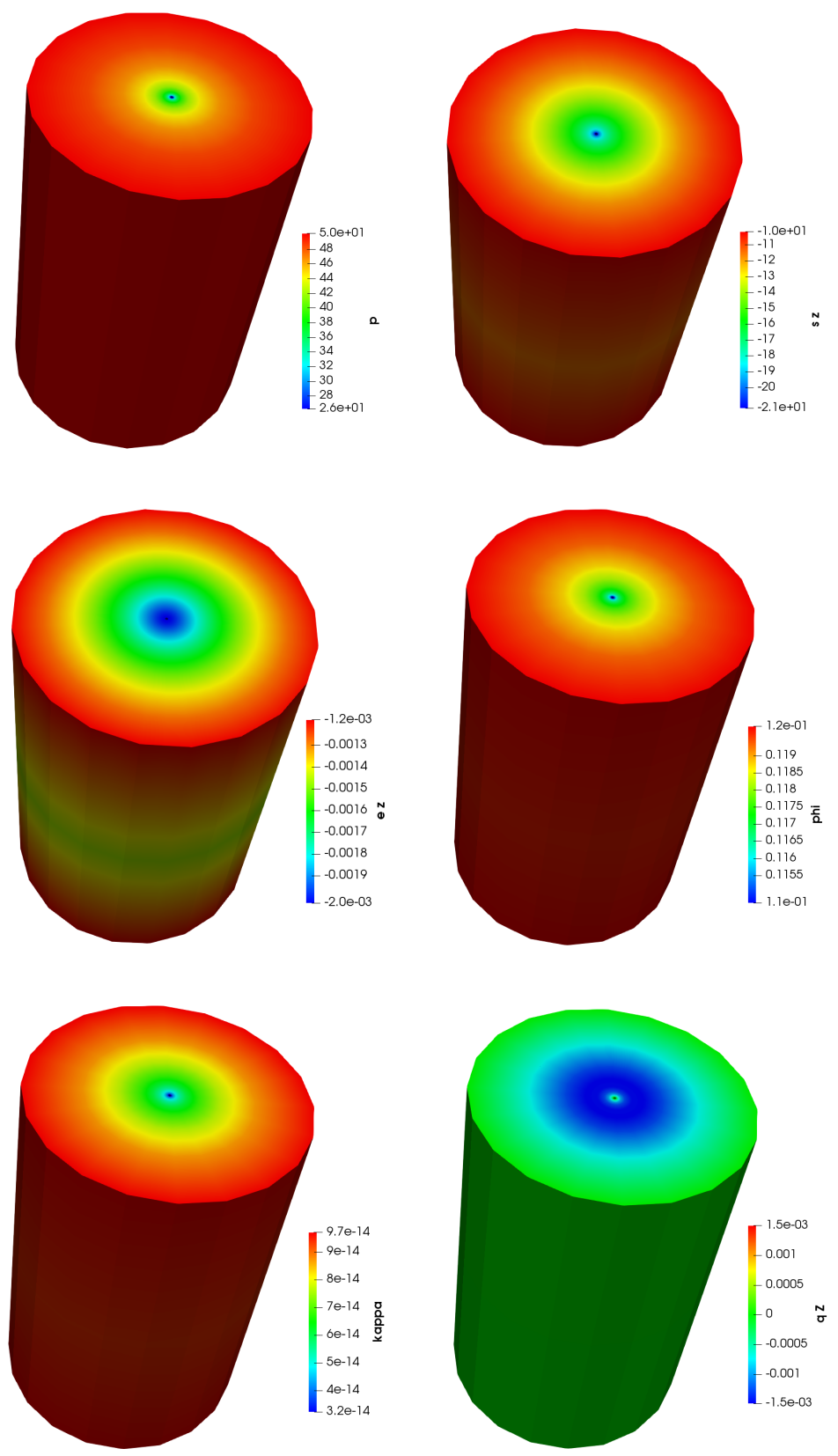

Figure 17. Distribution of variables in a $3 D$ cylindrical reservoir after 10 days. (topleft) fluid pressure, (top-right) effective stress, (middle-left) strain, (middle-right) porosity, (bottom-left) permeability, and (bottom-right) flux. 


\section{Conclusions}

The strain-dependent permeability on the productivity of reservoirs is analyzed using the coupled reservoir geomechanical modeling, in which the DiMaggio-Sandler elastoplasticity model and four nonlinear permeability models, e.g., Costa, Petunin, Nelson, and Davies are applied. The results show that by decreasing fluid pressure, the effective stress increases, and then the quantity of porosity and permeability decrease. The results also indicate that by increasing the permeability coefficient $\mathcal{Z}$, less increments of radial flux and more reduction of porosity and permeability near to the wellbore can be observed. In addition, the strain-dependent permeability in a $3 D$ cylindrical reservoir that receives a decrease and an increase of wellbore pressure is analyzed. The results emphasize that the wellbore lost some percent of porosity and permeability by decreasing and increasing of fluid pressure because of elastoplastic deformation. Finally, the results of strain-dependent permeability illustrate that from only geomechanical effects the wellbore region deteriorates the productivity index associated with the case when is considered a constant permeability and no geomechanical effects.

\section{Acknowledgements}

The authors M. Sanei, O. Durán, P.R.B. Devloo thankfully acknowledge financial support from ANP-Brazilian National Agency of Petroleum, Natural Gas and Biofuels (ANP-PETROBRAS) (grant 2014/00090-2). P.R.B. 
Devloo also acknowledges financial support from FAPESP, Brazil - Fundação de Amparo à Pesquisa do Estado de São Paulo, Brazil (grant 2017/157363), and from CNPq - Conselho Nacional de Desenvolvimento Científico e Tecnológico (grant 310369/2006-1).

\section{References}

Armero, F. (1999). Formulation and finite element implementation of a multiplicative model of coupled poro-plasticity at finite strains under fully saturated conditions. Computer Methods in Applied Mechanics and Engineering, 171(3-4), 205-241.

Biot, M. A. (1941a). Consolidation settlement under a rectangular load distribution. Journal of Applied Physics, 12(5), 426-430.

Biot, M. A. (1941b). General theory of three-dimensional consolidation. Journal of Applied Physics, 12(2), 155-164.

Biot, M. A. (1955). Theory of elasticity and consolidation for a porous anisotropic solid. Journal of Applied Physics, 26(2), 182-185.

Biot, M. A. (1962). Mechanics of deformation and acoustic propagation in porous media. Journal of Applied Physics, 33(4), 1482-1498.

Bui, T. A., Wong, H., Deleruyelle, F., Zhou, A., \& Lei, X. (2016). A coupled poroplastic damage model accounting for cracking effects on both hydraulic 
and mechanical properties of unsaturated media. International Journal for Numerical and Analytical Methods in Geomechanics, 40(5), 625-650.

Capasso, G., Musso, G., \& Mantica, S. (2008). Long-term stability study of open-hole completions in a producing hydrocarbon field. In The 42nd U.S. Rock Mechanics Symposium (USRMS), California: ISRM.

Carman, P. (1937). Fluid flow through granular beds. AIChE, 15(150).

Cecílio, D. L., Devloo, P. R., Gomes, S. M., dos Santos, E. R., \& Shauer, N. (2015). An improved numerical integration algorithm for elastoplastic constitutive equations. Computers and Geotechnics, 64, 1-9.

Costa, A. (2006). Permeability-porosity relationship: A reexamination of the kozeny-carman equation based on a fractal pore-space geometry assumption. Geophysical Research Letters, 33(2).

Coussy, O. (1995). Mechanics of Porous Continua. Wiley.

Coussy, O. (2004). Poromechanics. Wiley.

da Silva, R., Murad, M., \& Obregon, J. (2018). A new fixed-stress split scheme in poroplastic media incorporating general plastic porosity constitutive theories. In ECMOR XVI - 16th European Conference on the Mathematics of Oil Recovery: EAGE Publications BV.

Dautriat, J., Gland, N. F., souhail Youssef, Rosenberg, E., \& Bekri, S. (2007). 
Stress-dependent permeabilities of sandstones and carbonates: Compression experiments and pore network modelings.

David, C., Wong, T.-F., Zhu, W., \& Zhang, J. (1994). Laboratory measurement of compaction-induced permeability change in porous rocks: Implications for the generation and maintenance of pore pressure excess in the crust. Pure and Applied Geophysics PAGEOPH, 143(1-3), 425-456.

Davies, J. \& Davies, D. (1999). Stress-dependent permeability: Characterization and modeling. In SPE Annual Technical Conference and Exhibition: Society of Petroleum Engineers.

Davis, R. O. \& Selvadurai, A. P. S. (2002). Plasticity and Geomechanics. Cambridge University Press.

de Souza Neto, E. A., Peri, D., \& Owen, D. R. J. (2008). Computational Methods for Plasticity. John Wiley Sons, Ltd.

Dean, R. H., Gai, X., Stone, C. M., \& Minkoff, S. E. (2006). A comparison of techniques for coupling porous flow and geomechanics. SPE Journal, 11(01), 132-140.

Devloo, P. R. B. (1997). PZ: An object oriented environment for scientific programming. Computer Methods in Applied Mechanics and Engineering, 150(1-4), 133-153.

Devloo, P. R. B. (2000). Object oriented tools for scientific computing. Engineering with Computers, 16(1), 63-72. 
DiMaggio, F. \& Sandler, I. (1971). Material model for granular soils. Journal of the Engineering Mechanics Division, 97, 935-950.

Duŕan, O., Sanei, M., Devloo, P., \& Santos, E. (2019). An enhanced sequential fully implicit scheme for reservoir geomechanics. Computer and Geoscience.

Fossum, A., Senseny, P., Pfeifle, T., \& Mellegard, K. (1995). Experimental determination of probability distributions for parameters of a salem limestone cap plasticity model. Mechanics of Materials, 21(2), 119-137.

Ghabezloo, S., Sulem, J., Guédon, S., \& Martineau, F. (2009). Effective stress law for the permeability of a limestone. International Journal of Rock Mechanics and Mining Sciences, 46(2), 297-306.

Gutierrez, M. S. \& Lewis, R. W. (2002). Coupling of fluid flow and deformation in underground formations. Journal of Engineering Mechanics, 128(7), 779-787.

Han, G. \& Dusseault, M. B. (2003). Description of fluid flow around a wellbore with stress-dependent porosity and permeability. Journal of Petroleum Science and Engineering, 40(1-2), 1-16.

Holt, R. M. (1990). Permeability reduction induced by a nonhydrostatic stress field. SPE Formation Evaluation, 5(04), 444-448.

Jiang, J. \& Yang, J. (2018). Coupled fluid flow and geomechanics modeling 
of stress-sensitive production behavior in fractured shale gas reservoirs. International Journal of Rock Mechanics and Mining Sciences, 101, 1-12.

Kim, J. (2010). Sequential Methods for Coupled Geomechanics and Multiphase Flow. PhD thesis, Stanford University. The Department of Energy Resources Engineering.

Kim, J., Sonnenthal, E. L., \& Rutqvist, J. (2012). Formulation and sequential numerical algorithms of coupled fluid/heat flow and geomechanics for multiple porosity materials. International Journal for Numerical Methods in Engineering, 92(5), 425-456.

Kim, J., Tchelepi, H., \& Juanes, R. (2011a). Stability and convergence of sequential methods for coupled flow and geomechanics: Drained and undrained splits. Computer Methods in Applied Mechanics and Engineering, 200(23-24), 2094-2116.

Kim, J., Tchelepi, H., \& Juanes, R. (2011b). Stability and convergence of sequential methods for coupled flow and geomechanics: Fixed-stress and fixed-strain splits. Computer Methods in Applied Mechanics and Engineering, 200(13-16), 1591-1606.

Kim, J., Tchelepi, H. A., \& Juanes, R. (2011c). Stability, accuracy, and efficiency of sequential methods for coupled flow and geomechanics. SPE Journal, 16(02), 249-262. 
Kossa, A. (2011). Exact stress integration schemes for elastoplasticity. PhD thesis, Budapest University of Technology and Economics.

Kozeny, J. (1927). Uber kapillare leitung des wassers im boden. Ber. Wien Akad., (136A), 271-306.

Lim, J.-S. \& Kim, J. (2004). Reservoir porosity and permeability estimation from well logs using fuzzy logic and neural networks.

Ma, J. (2015). Review of permeability evolution model for fractured porous media. Journal of Rock Mechanics and Geotechnical Engineering, 7(3), $351-357$.

Main, I. G., Kwon, O., Ngwenya, B. T., \& Elphick, S. C. (2000). Fault sealing during deformation-band growth in porous sandstone. Geology, 28(12), 1131.

Mikelić, A. \& Wheeler, M. F. (2012). Convergence of iterative coupling for coupled flow and geomechanics. Computational Geosciences, 17(3), 455461.

Minkoff, S. E., Stone, C., Bryant, S., Peszynska, M., \& Wheeler, M. F. (2003). Coupled fluid flow and geomechanical deformation modeling. Journal of Petroleum Science and Engineering, 38(1-2), 37-56.

Morris, J. P., Lomov, I. N., \& Glenn, L. A. (2003). A constitutive model for stress-induced permeability and porosity evolution of berea sandstone. Journal of Geophysical Research: Solid Earth, 108(B10). 
Nelson, P. (1994). Permeability-porosity relationships in sedimentary rocks. Society of Petrophysicists and Well-Log Analysts.

Ni, X., Chen, Z., Wang, P., Wu, J., Wu, Y., \& Gong, P. (2018). Experimental investigation of the influence of differential stress, confining pressure and strain on aquifer sandstone permeability. European Journal of Environmental and Civil Engineering, (pp. 1-16).

Pan, F., Sepehrnoori, K., \& Chin, L. Y. (2009). A new solution procedure for a fully coupled geomechanics and compositional reservoir simulator. In SPE Reservoir Simulation Symposium: Society of Petroleum Engineers.

Park, K. C. (1983). Stabilization of partitioned solution procedure for pore fluid-soil interaction analysis. International Journal for Numerical Methods in Engineering, 19(11), 1669-1673.

Petunin, V., Tutuncu, A., Prasad, M., Kazemi, H., \& Yin, X. (2011). An experimental study for investigating the stress dependence of permeability in sandstones and carbonates. 45th U.S. Rock Mechanics / Geomechanics Symposium, 9(ARMA-11-279).

Phillips, P. J. \& Wheeler, M. F. (2007). A coupling of mixed and continuous galerkin finite element methods for poroelasticity i: the continuous in time case. Computational Geosciences, 11(2), 131-144.

Raghavan, R. \& Chin, L. (2004). Productivity changes in reservoirs with 
stress-dependent permeability. SPE Reservoir Evaluation \& Engineering, 7(04), 308-315.

Rhett, D. W., . T. L. W. (1992). Stress path dependence of matrix permeability of north sea sandstone reservoir rock. American Rock Mechanics Association.

Rudnicki, J. W. (1986). Fluid mass sources and point forces in linear elastic diffusive solids. Mechanics of Materials, 5(4), 383-393.

Ruistuen, H., Teufel, L., \& Rhett, D. (1999). Influence of reservoir stress path on deformation and permeability of weakly cemented sandstone reservoirs. SPE Reservoir Evaluation \&3 Engineering, 2(03), 266-272.

Sandler, I. S. \& Rubin, D. (1979). An algorithm and a modular subroutine for the CAP model. International Journal for Numerical and Analytical Methods in Geomechanics, 3(2), 173-186.

Sanei, M., Duran, O., \& Devloo, P. R. (2017). Finite element modeling of a nonlinear poromechanic deformation in porous media. In Proceedings of the XXXVIII Iberian Latin American Congress on Computational Methods in Engineering: ABMEC Brazilian Association of Computational Methods in Engineering.

Santos, E., Borba, A., \& Ferreira, F. (2014). Stress-dependent permeability measurement of indiana limestone and silurian dolomite samples in 
hydrostatic tests. International Society for Rock Mechanics and Rock Engineering, Goiania, Brazil, 04.

Schatz, J. F., Ahmed, U., \& Carroll, M. (1982). Reservoir performance changes due to inelastic deformation. In SPE Formation Damage Control Symposium: Society of Petroleum Engineers.

Schutjens, P., Hanssen, T., Hettema, M., Merour, J., de Bree, P., Coremans, J., \& Helliesen, G. (2004). Compaction-induced porosity/permeability reduction in sandstone reservoirs: Data and model for elasticity-dominated deformation. SPE Reservoir Evaluation \& Engineering, 7(03), 202-216.

Settari, A. \& Mourits, F. (1998). A coupled reservoir and geomechanical simulation system. SPE Journal, 3(03), 219-226.

Settari, A. \& Walters, D. A. (2001). Advances in coupled geomechanical and reservoir modeling with applications to reservoir compaction. SPE Journal, 6(03), 334-342.

Shin, H. S., Kim, K. Y., \& Pande, G. N. (2014). On computation of straindependent permeability of rocks and rock-like porous media. International Journal for Numerical and Analytical Methods in Geomechanics, 39(8), $821-832$.

Teklu, T. W., Zhou, Z., Li, X., \& Abass, H. (2016). Experimental investigation on permeability and porosity hysteresis in low-permeability formations. 
Terzaghi, K. (1925). Erdbaumechanik auf bodenphysikalischer grundlage. Franz Deutikle, Leipzig und Wien.

Tran, D., Nghiem, L., \& Buchanan, L. (2005). Improved iterative coupling of geomechanics with reservoir simulation. In SPE Reservoir Simulation Symposium: Society of Petroleum Engineers.

Walsh, J. B. \& Brace, W. F. (1984). The effect of pressure on porosity and the transport properties of rock. Journal of Geophysical Research, 89(B11), 9425.

Wei, Z. \& Zhang, D. (2010). Coupled fluid-flow and geomechanics for tripleporosity/dual-permeability modeling of coalbed methane recovery. International Journal of Rock Mechanics and Mining Sciences, 47(8), 12421253.

Wheeler, M. F. \& Gai, X. (2007). Iteratively coupled mixed and galerkin finite element methods for poro-elasticity. Numerical Methods for Partial Differential Equations, 23(4), 785-797.

Xie, S. Y. \& Shao, J. F. (2015). An experimental study and constitutive modeling of saturated porous rocks. Rock Mechanics and Rock Engineering, 48(1), 223-234.

Xu, T., Tang, C., \& Li, L. (2008). A coupled model for brittle porous rocks with stress dependent of permeability. International Society for Rock Mechanics and Rock Engineering. 
Yale, D. (2002). Coupled geomechanics-fluid flow modeling: Effects of plasticity and permeability alteration.

Yale, D., Lyons, S., \& Qin, G. (2000). Coupled geomechanics-fluid flow modeling in petroleum reservoirs: Coupled versus uncoupled response. 4 th North American Rock Mechanics Symposium, Seattle, Washington, (0137).

Yale, D. P. \& Crawford, B. (1998). Plasticity and permeability in carbonates: Dependence on stress path and porosity.

Zhou, H., Jia, Y., \& Shao, J. (2008). A unified elastic-plastic and viscoplastic damage model for quasi-brittle rocks. International Journal of Rock Mechanics and Mining Sciences, 45(8), 1237 - 1251.

Zhou, X., Zeng, Z., \& Liu, H. (2011). Stress-dependent permeability of carbonate rock and its implication to co2 sequestration. American Rock Mechanics Association.

Zhu, W. \& fong Wong, T. (1997). The transition from brittle faulting to cataclastic flow: Permeability evolution. Journal of Geophysical Research: Solid Earth, 102(B2), 3027-3041.

Zimmerman, R. W. (1991). Compressibility of Sandstones (Developments in Petroleum Science). Elsevier Science Ltd. 